Verdammungsurtheil, durch welches Riehm am Schlusse seiner Recension die theologische Wissenschaft vor kirchlicher Censurirung meint schützen zu sollen, dürfte bedeutend an Gewicht verlieren, wenn man sieht, wie er unbewufst und unbefangen dasselbe Verfahren, das er in dem Schlufssatze - allerdings in schwerlich zu billigender Schärfe der Fassung unter unberechtigter Berufung auf mein Buch S. 145 - rügt, in seiner Recension selbst mehrfach (z. B. S. 772 f. 778 f.) und in ziemlich ausgiebigem Umfạng handhabt. Oder bedingt das einen Unterschied, wenn er solche Vorgänge in die Verarbeitung der mündlichen Ueberlieferung verlegt, während ich aus ihnen die Zusammenschichtung der schriftlichen zu erklären suche? Mich dünkt, nur den, dafs ich eine höhere Schätzung der biblischen Schriftsteller vertrete, als Riehm, indem ich nicht ihnen selbst, sondern Redactorenhänden die Vereinigung widersprechender Ueberlieferungen zutraue.

\title{
Philister und Hebräer zur Zeit Davids.
}

\section{Von Adolf Kamphausen.}

Nicht um eine erschöpfende Darstellung des Verhältnisses, welches in der ältesten hebräischen Königszeit zwischen den Philistern und den Hebräern bestand, ist es mir jetzt zu thun, sondern ich möchte nur einige Bemerkungen mittheilen, welche vielleicht dies oder jenes in helleres geschichtliches Licht stellen helfen, zugleich aber einen Beitrag zu richtigerer Würdigung der Person Davids geben, den Ranke (Weltgesch. I, 1, S. 60. 63) als von Samuel gesalbten Propheten betrachtet, während der mit der neueren Kritik besser bekannte Ed. Meyer in seiner 
Geschichte des Alterthums (Erster Band. Stuttgart 1884) in anderer Weise noch viel zu wünschen übrig läfst.

1. Hatte Simson den Philistern nur wenig Abbruch thun können, so gelang es dem tapferen Saul bekanntlich viel besser, die schwer gedrúckten Hebräer von der Herrschaft des kleinen Nachbarvolkes zu befreien. Aber erst David konnte diese Befreiung vollständig durchführen, nachdem die Philister mit Sauls Tode den Gipfel ihrer Macht erreicht und Jahre lang von den beiden gleichzeitig zu Mahanaim und Hebron regierenden hebräischen Königen Tribut empfangen hatten. Schon in meiner Chronologie der hebräischen Könige (S. 79, Anm. 31) habe ich es als wahrscheinlich bezeichnet, daIs Isboseth zu Mahanaim eben so gut als David zu Hebron in einem Vasallenverhältnifs zu den Philistern stand. Es sei mir gestattet, diese $\mathrm{Hy}$ pothese jetzt zu begründen, da sie der herrschenden Ansicht, welche ich um der angeblichen Grolsthaten Abners willen kurz die Eroberer-Hypothese nenne, stark genug zuwiderläuft.

Bekanntlich macht die den Zusammenhang unterbrechende chronologische Notiz 2 Sam. 2, 11 in Vergleich mit dem andern Einschiebsel, welches in v. $10 \mathrm{a}$ vorhergeht, eine gewisse Schwierigkeit, obgleich die Notiz von dem siebenundeinhalbjährigen Königthum Davids zu Hebron sich durch innere Glaubwürdigkeit empfiehlt und an 2 Sam. 5, 4. 5 eine unverächtliche Stütze besitzt. Zwar schreibt noch v. Orelli in seinem Artikel über David (Herzog's RE.2 III, 516) : ${ }_{\text {Da }}$ Isboseth nur 2 Jahre regierte, scheint David auch nach seiner Anerkennung durch Gesammtisrael noch eine Zeitlang im judäischen Hebron verweilt zu haben (andere Möglichkeit s. Ewald, Gesch. III, 154)." Aber diese Lösung der in dem Unterschiede von 2 und $71 / 2$ Jahren liegenden Schwierigkeit (2 Sam. 2, $10 \mathrm{f}$.) ist doch so unnatürlich als möglich. Mit Recht bemerkt Keil (Die Bücher Samuels ${ }^{2}$ 233), die Annahme von Seb. Schm. Cler. 
u. A., dafs David nach Isboseths Ermordung 5 $\frac{1}{2}$ Jahre über ganz Israel zu Hebron regiert habe, streite mit den klaren Textesworten : „David war König zu Hebron über das Haus Juda $71 / 2$ Jahre." Wohl eben so sehr spricht gegen das $5^{1} / 2$ jährige „Verweilen in Hebron " nach Isboseths Tod die einfache Erwägung, dafs die Erhebung Davids zum Könige über ganz Israel den Krieg mit den Philistern grade so nothwendig machte, als früher die Wahl Sauls zum Könige über alle Stämme den Kampf mit den übermächtigen Feinden unvermeidlich gemacht hatte. Den Krieg aber mit den Philistern, welcher sich schwerlich über die beiden ersten Jahre von Davids Regierung über ganz Israel hinauserstreckte, führte David nicht von Hebron, sondern von Jerusalem aus, wie schon die wiederholte (2 Sam. 5, 18. 22) Erwähnung des Rephaiterthales zeigt. Auch das ist undenkbar, dals nach Isboseths Ermordung seine bisherigen Unterthanen sich über fünf Jahre besonnen haben sollten, ehe sie David als König über sich anerkannten. Was man von Saul erwartete, als man die ganze Volkskraft in seiner Hand vereinigte, dasselbe erhofften nach Sauls Tode die Israeliten schon bei Lebzeiten Isboseths von David, wie Abners Verhandlungen (2 Sam. 3, $17 \mathrm{ff}$.) mit den Aeltesten Israels deutlich zeigen; wiederum oder noch immer handelt sich's um die Befreiung des Volkes Israel von der Philister Hand. Es ist wohl selbstverständlich, dafs David, der als König über sein ganzes Volk nicht länger tief im Süden zu Hebron residiren konnte, alsbald nach der 2 Sam. 5, 3 erzählten Salbung sich nach einem festen Stützpunkt in dem unvermeidlich gewordenen Kriege mit den Philistern umsah. Diesen Stützpunkt fand er durch die rasche Eroberung Jerusalems, und erst auf diese folgten die entscheidenden, nur in aller Kürze 2 Sam. 5, 17-25 erzählten grofsen Schlachten, welche die Obmacht der Philister (2 Sam. 8, 1) gründlich brachen. 
Doch kehren wir zu den angeblich 2 Jahren der Regierung des Isboseth zurück, so scheint, da Keil dieselben mit gutem Grunde nicht von der Zeit bis zum Kriege mit David verstehen will, nichts anderes übrig zu bleiben als Ewald's zienlich herrschend gewordene (vgl. Aug. Köhler, Lehrbuch der Bibl. Gesch. II, S. 247)

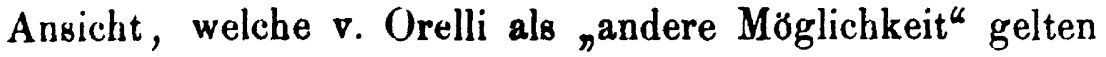
läfst; die Meinung, dafs Isboseth erst geraume Zeit nach Saul's 'Tode zum Königthum gelangt sei. So ist für Keil die kurze Dauer von Isboseths Königthum nur daraus erklärlich, dafs er erst König wurde, „nachdem das von den Philistern besetzte Land diesseit des Jordan durch Abner wieder erobert worden war, worüber gegen 5 Jahre vergehen mochten. ${ }^{*}$ Unstreitig werden die überschiefsenden $5 \frac{1}{2}$ Jahre vollständig untergebracht, wenn man sich den Abner während dieser Zeit als grofsen Eroberer thätig denkt; wenn nur diese Eroberer-Hypothese sich geschichtlich irgend wahrscheinlich machen liefse! Mag dieselbe aber auch durch harmonistisches Interesse hervorgerufen sein, thatsächlich hat sie sich auch nach dem Schwinden des letzteren behauptet, selbst nachdem 2 Sam. 2, 10a, welchen Halbvers Wellhausen (Bleek ${ }^{4} 222$; vgl. die frühere ausführliche Aeufserung Wellhausen's, Der Text der Bücher Samuelis, S. 154) als Einschiebsel erkannte, preisgegeben worden war. Noch in seinem $\mathrm{Ab}$ rifs der Geschichte Israels und Juda's bemerkt Wellhausen (Skizzen und Vorarbeiten I, S. 24) nach Sauls Fall am Berge Gilboa : „Die Niederlage schien das Werk seines Lebens zu vernichten. Zunächst wenigstens gewannen die Philister die verlorene Herrschaft über das westjordanische Land wieder. Aber jenseit des Jordans machte Abner, Sauls Vetter und Feldhauptmann, dessen noch unmündigen Sohn Isbaal zum Könige in Mahanaim, und es gelang ihm von hier aus die Herrschaft des Hauses Saul über Jezreel, Ephraim und Benjamin wieder auszudehnen, natürlich im 
fortgehenden Kampfe mit den Philistern. Nur Juda gewann er nicht." Aehnlich behauptet z. B. Guthe in seinem Artikel Isboseth (Herzog RE. ${ }^{2}$ ) : „Isboseth ist nicht zwei, sondern etwa sieben Jahre, fast die ganze Zeit der Herrschaft Davids zu Hebron, König gewesen", ohne mit Wellhausen zu bemerken, dafs sich die Zweizahl hier genau so wie 1 Sam. 13, 1 erkläre. Dann aber fährt Guthe fort : „Abner muls die Philister bald zurückgedrängt haben; denn 2 Sam. 2, 12 finden wir ihn auf dem Wege nach Gibeon, um für seinen Schützling gegen Davids, von Joab geführtes Heer zu kämpfen." Gewifs mufste Abner, um Juda zu bekämpfen, vor der Bekriegung durch die Philister sicher sein, welche bei Sauls Tod offenbar mächtiger waren, als je zuvor. Wir brauchen jedoch nicht anzunehmen, dafs Abner diese Sicherheit durch grofse Siege über die Philister, von welchen die Geschichte nichts weifs, gewonnen hätte. Abner gewann auch Ruhe vor den übermächtigen Philistern, wenn er sich ihnen in irgendeiner Form unterwarf. Von solcher Unterwerfung schweigt der dürftige biblische Bericht ebenfalls. Dennoch meine ich, das Verschweigen einer wenig rühmlichen Unterwerfung lasse sich viel leichter erklären, als dafs die ruhmvollen Thaten des die israelitischen Gebiete zurückerobernden Abner übergangen sein sollten.

In Wirklichkeit erklärt sich die Zähigkeit der ErobererHypothese wohl hauptsächlich daraus, dafs man im biblischen Text selbst die allmähliche Rückeroberung ausgesprochen zu tinden meinte. Man liefs sich blenden durch Ewald's (Gesch. ${ }^{3}$ III 154) scharfsinnige Vermuthung, dafs in der Reihenfolge der 2 Sam. 2, 9 genannten Gebietstheile „die Ordnung beschrieben sei, in welcher Abner die von den Philistäern besetzten Länder zurückeroberte. “ Wenn Ed. Meyer in seiner Geschichte des Alterthums (I, § 297) Abners Verdienst um Sauls Reich lobt, so will ich dasselbe nicht schmälern und kann den Worten : ${ }_{n}$ Sauls 
Reich schien vernichtet. Dasselbe gerettet zu haben, ist das Verdienst seines Feldhauptmanns Abiner. In Machanaim in Gile'ad sammelte er die Kräfte des Königthums um Saul's Sohn Ižba'al " unbedenklich beistimmen, sofern ich nicht bezweifle, dafs Abner mit dem Rest der israelitischen Krieger den schwerlich noch unmündigen, aber doch in jugendlichem Alter stehenden und jedenfalls sehr schwachen Isboseth nach dem sicheren Mahanaim brachte und ibn hier zum König über ganz Israel ausrief. Um so bedenklicher aber sind mir zum Theil die dann folgenden Worte

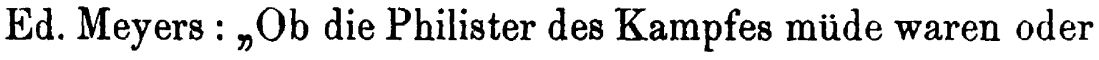
geschlagen wurden, wissen wir nicht; genug, dem Abiner gelang es, Išbáals Königthum über das ganze eigentliche Israel, d. h. Giléad, Joseph und die Nordstämme, wieder herzustellen." Wo die historische Ueberlieferung durch abgerissene, lückenhafte Darstellung uns ein Räthsel aufgiebt, haben wir Recht und Pflicht, dasselbe durch Vermuthungen zu lösen, welche sich durch innere Wahrscheinlichkeit empfehlen. Mit den beiden Möglichkeiten der Ermüdung oder der Besiegung der Philister ist $\mathrm{m}$. E. nicht ernstlich zu rechnen. Sehr richtig giebt Meyer zu, dafs der biblische Text von Eroberungen oder Siegen Abners nichts meldet, aber er hat keine Antwort auf die Frage, wie es denn geschichtlich denkbar ist, dals dem Abner die Aufrichtung von Isboseths Königthum überhaupt gelingen konnte. Wer sich die Macht der Philister bei Sauls Tod recht vor Augen stellt und es selbstverständlich findet, dafs die Sieger nicht freiwillig auf ihren Siegespreis verzichteten, für den bleibt, wie mir scheint, nur folgende Alternative. Entweder muls er gütliche Verständigung Abners mit den Philistern annehmen, wobei sich die Sieger natürlich ihren Vortheil gewahrt haben werden, wenn sie auch vielleicht dem neuen Könige keinen sehr schweren Tribut auferlegten, oder er muls den Abner zum grofsen Eroberer machen. Ich glaube, dals Ewald hier in der 
Wahl sich vergriffen hat, mufs aber die Entschiedenheit loben, mit welcher er Abners Verdienst feiert. Es fällt Ewald nicht ein, von blofsem Zurückgedrängtwerden oder Zurückweichen der Philister zu reden, sondern er preist den tapferen Abner wegen der glücklichen Lösung seiner sehr schwierigen Aufgabe und meint, dafs die Philister nicht so leichten Kaufes ihre Eroberungen, in denen sie sich schon festgesetzt hatten, wieder aufgegeben haben würden. Ebenso läfst Aug. Köhler (II, S. 246) den kühnen und unternehmungslustigen Abner einen mehr als fünfjährigen schweren Kampf gegen die Philister führen, wodurch er das ganze westjordanische Israel bis zur Nordgrenze des Reiches Juda erobert habe.

Die Gestalt des grofsen Kriegshelden Abner, von dessen Grofsthaten die Geschichte sonst nichts meldet, nimmt dadurch noch gröfsere Verhältnisse an, dafs er zu Gunsten des Hauses Saul zwei nicht unverächtliche Feinde zu bekriegen unternahm, wenn man der gewöhnlichen Auffassung folgt, nicht nur die Philister, sondern auch den judäischen König David, welchen er ja erst kurz vor seinem Tode als rechtmälsigen Herrscher anerkennen konnte. Stade (Gesch. des Volkes Israel, S. 257) sagt daher, die Dynastie Sauls habe mehrere Jahre unter Leitung Abners einen nicht unrühmlichen Kampf gegen diese beiden Feinde gekämpft. Geschichtlich leichter vorstellbar wird die Sache, wenn Abner zuerst den Philistern gegenüber seine Rückeroberungen vollendete und dann erst den König David bekriegte, der ihm als Usurpator galt. Das ist denn auch die gewöhnliche Meinung, der z. B. Ewald und Köhler folgen, und der letztere Gelehrte hat dabei, wie wir später sehen werden, den grofsen Vortheil, dafs er sich den David in Hebron nicht als Vasallen der Philister denkt, sondern als selbständigen König. Dürfen wir Abner als den grofsen Eroberer betrachten, so war es gewifs seine erste Aufgabe, die Nordisraeliten

Zeitschrift f. d. alttest Wiss. Jahrgang 6.1886. 
von den Philistern zu befreien; das lag ihm am nächsten, mochte seine Erbitterung gegen den Usurpator David auch noch so grofs sein. Erst nachdem ganz Israel, nur Juda ausgenommen, wieder dem Hause Sauls gewonnen und ein von den Philistern unabhängiges Reich geworden war, konnte Abner, wie es scheint, „die Eroberung des Reiches Juda als seine nächstfolgende Aufgabe betrachten* (Köhler). Niemand wird gerne annehmen, dafs Abner die beiden gefährlichen Gegner, die Philister und den König von Juda gleichzeitig bekriegt habe; vom Standpunkt der geschichtlichen Wahrscheinlichkeit aus hat Guthe mit Recht das Gegentheil als selbstverständlich vorausgesetzt. Aber so ganz von selbst versteht sich dies doch nicht; wenn Abner der grolse Eroberer sein soll, so ist an der Gleichzeitigkeit seines Kämpfens gegen die Philister und gegen Juda schwerlich ganz vorbeizukommen.

Meines Erachtens leidet die Meinung, Abner habe in langen schweren Kämpfen die Philister besiegt und dann erst Juda bekriegt, an grofser innerer Unwahrscheinlichkeit, mag David in Hebron Vasall der Philister gewesen sein, oder nicht. Betrachten wir, was ich für irrig halte, mit Köhler das Königthum Juda als ein ganz selbständiges Reich, so würde also David es ruhig haben geschehen lassen, dafs Abner in jahrelangem Krieg einen Vortheil nach dem andern über die Philister errang, während der kluge Judäer, dem Abners Hals nicht verborgen sein konnte, sich sagen mufste, dals nach Besiegung der Philister durch den israelitischen Feldhauptmann die Reihe an ihn selbst kommen würde. Man darf ja nicht übersehen, dafs durch den Tod des Saul und seiner kriegstïchtigen Söhne die Sachlage für David sich sehr verändert hatte. Gegen seinen rechtmäfsigen König Saul hat David niemals die Waffen erhoben. Ich kann zwar nicht mit Köhler (II, S. 245) aus 2 Sam. 2, 4b-7 herauslesen oder auch nur an sich wahrscheinlich finden, dafs David, dessen Salbung 
durch Samuel mir als ungeschichtlich gilt, israelitische Stämme zu freiwilligem Anschlufs an sein Reich aufgefordert habe. Wohl aber halte ich es für sicher, dafs David sein Königthum über Juda als ein durchaus rechtmälsiges ansah und von Anfang an gegen Abner zu vertheidigen entschlossen war. Nach der durchaus glaubwürdigen biblischen Darstellung hat sich David dem Isboseth gegenüber thatsächlich immer nur im Zustande der Vertheidigung befunden und ist seinerseits nie zum offenen Angriff vorgeschritten; die Dinge fügten sich so glücklich, dafs David niemals zum Angriff auf seine eigenen Landsleute und Religionsgenossen genöthigt wurde. Diese Gehässigkeit, vor der Saul und Abner keineswegs zurückschreckten, blieb dem klugen Judäer erspart, wie sehr auch der Schein mitunter gegen ihn sprechen mochte. Trotzdem möchte ich David keineswegs für ein solches Lamm halten, dafs er, anstatt sich mit den Philistern gegen Abner zu verbünden, ruhig zugesehen haben sollte, wie sein Todfeind die Macht der Philister so sehr brach, dafs diese auf ihr eigenes Gebiet sich beschränkt sahen. War Abner der grofse Eroberer, für welchen man ihn, hält, so erscheint's rätbselhaft, dafs David nicht zu seiner eigenen Sicherheit rechtzeitig mit den Philistern ihm entgegentrat; war erst die Macht der Philister in der eben angegebenen Weise gebrochen, so blieb für David keine Hoftnung auf erfolgreichen Widerstand gegen den ihm ungerecht erscheinenden Angriff des siegreichen Eroberers mehr übrig.

Ehe ich den andern und m. E. allein der geschichtlichen Wirklichkeit entsprechenden Fall in's Auge fasse, wonach David als Vasall der Philister in Hebron residirte, will ich nochmals hervorheben, dafs ich mich keiner Uebertreibung schuldig zu machen glaube, wenn ich der gewöhnlichen Ansicht von Abner zur Last lege, dafs sie die Macht der Philister durch Sauls Feldhauptmann gebrochen werden lasse, und zwar in noch höherem Grade, als dies durch 
den 1 Sam. 14 erzählten Sieg Sauls geschehen sein kann. Die lobende Uebersicht über die Heldenthaten des ersten Königs, welche wir 1 Sam. 14, 47 f. aus der alten Saulsgeschichte lesen, darf als wesentlich geschichtlich gelten; obgleich wohl erst David mit den Aramäern von Zoba siegreich gekämpft hat, sind doch die Kriege Sauls mit den Ammonitern und Amalekitern genügend verbürgt. Mit einem gewissen Recht sagt Wellhausen (Bleek ${ }^{4}$ 214) : ${ }_{n}$ Saul hat sein Lebetage lang sich gegen die Philister zu wehren gehabt"; um so leichter begreift sich's, dal's auch einmal die benachbarten Moabiter und Edomiter sich eine bedrängte Lage Israels zu Nutze machten und bald darauf von Saul glücklich zurückgeworfen oder gar auf ihrem eigenen Gebiete heimgesucht wurden. Wenn aber Wellhausen den Beweis für die Behauptung, dafs erst David die Kriege mit Moab und Edom geführt habe, schuldig geblieben ist, so kann er durch die an sich richtige Bemerkung, das Erliegen Sauls im Kampfe mit den Philistern werde in der Zusammenfassung 1 Sam. 14, 47 von dem für Saul eingenommenen Verfasser, , verschwiegen ${ }^{4}$ noch viel weniger der Glaubwürdigkeit dieses alten Erzählers zu nahe treten. Es ist doch ganz selbstverständlich, dals der Verfasser der innerhalb 1 Sam. 8-14 bruchstücksweise uns erhaltenen Geschichte Sauls, mochte er noch so sehr das Erfreuliche in der Regierung seines Helden hervorheben, unmöglich den traurigen Tod des Saul verschweigen konnte, dals er vielmehr am geeigneten Orte das Erliegen des ersten Königs vor den Philistern erzählen mu ste. Durch seine scharfsinnige und in hohem Grade gelungene Quellenscheidung hat Wellhausen selber die Annahme nöthig gemacht, dafs uns von der alten Saulsge- schichte nur wenige Bruchstücke erhalten geblieben sind. Aufser einer gewissermafsen abschliefsenden, aber nicht in ursprünglicher Form erhaltenen Zusammenfassung besitzen wir aus jener Saulsgeschichte ja nur die Erzählung von 
Sauls Erhebung zum Konigthum und von dem ersten grofsen Siege über die Philister, der Israel zwar Luft machte, aber weitere Kämpfe zur Behauptung der Unabhängigkeit nicht ausschlofs. Ich bezweifle nicht, dafs der Verfasser der Saulsgeschichte den von ihm kurz (1 Sam. 14, 48) erwähnten Kriegszug Sauls gegen die Amalekiter vorher ausführlich beschrieben hatte; diese Beschreibung ist für uns, die wir darüber $1 \mathrm{Sam} .15$ aus einer anderen Quelle unterrichtet werden, vollständig weggefallen. Ebenso mufs dieser Erzähler, da Sauls erster grofser Sieg bei Michmas die Macht der Philister noch lange nicht ganz gebrochen hatte, wenn auch die bisherige Tributpłlichtigkeit Israels abgeschüttelt war, noch viele weitere Kämpfe Sauls mit den Philistern berichtet haben, darunter gewifs nicht wenige glückliche. Das alles, was die Saulsgeschichte unmöglich mit Stillschweigen übergehen konnte, ist bei der ältesten Redaction des Samuelbuchs einfach darum für uns weggefallen, weil es dem Redactor passender erschien, für die spätere Zeit des Saul die Davidsgeschichte zu benutzen. Da wirklich erst David es war, der die Macht der Nachbarvölker gründlich braçh, so trat für die spätere Betrachtung die strahlende Person Davids um so leichter in den Vordergrund, zumal da dieser schon als Diener Sauls den $\mathrm{Phi}$ listern gegenüber sich grofsen Ruhm erwarb. Gelegentlich erfahren wir aber doch einiges über Sauls Beziehungen zu den früheren Zwingherren seines Volks. Ich brauche hier die zerstreuten Notizen nicht zusammenzustellen; genügt doch schon die Nachricht, dafs „der Streit hart war wider die Philister, so lange Saul lebte", vergl. 1 Sam. 14, 52, welchen Vers ich mit Wellhausen als den alten Uebergang von der mit 14, 51 abschliefsenden Geschichte Sauls zu der 16, 14-23 beginnenden Geschichte Davids betrachte. Sehen wir auch ab von dem 1 Sam. 14, 30 ausgesprochenen Bedauern, dafs die Niederlage unter den Philistern nicht gröfser geworden sei, so viel steht auf 
jeden Fall fest, dafs der Sieg bei Michmas kein entscheidender war, der den Philistern die Lust benommen hätte, weiter mit Israel zu streiten. Im Gegentheil haben sie während der Regierung Sauls die Hoffnung auf Wiedergewinnung ihrer Oberherrschaft nie ganz aufgegeben. In dem tragischen Untergange des tapferen Saul, dessen langjährige Bemühungen schliefslich doch scheiterten, erreichte das kriegerische Philistervolk sein mit so grofser Zähigkeit verfolgtes Ziel. Saul oder, wie Stade (Gesch. S. 259 f.) sich ausdrückt, „das benjaminitische Königthum hatte sich unfähig erwiesen, das philistäische Joch zu brechen. " Wenn dieser selbe Gelehrte (S. 257, 261) sich näher dahin ausspricht : „Mit der Vertreibung der Philister aus Benjamin begann unter Saul das Ringen Israels um seine Freiheit. Als Saul fällt, geräth sogar die Kischonebene nebst den östlich vom Gilboagebirge gelegenen Städten in philistäische Gewalt. Saul hinterläfst seinem minderjährigen Sohn eine schlimme Erbschaft. - Auf dem Hause Sauls lastete die doppelte Aufgabe, einmal den ärger als je gewordenen Druck der Philister zu brechen, dann den entfremdeten Stamm Juda zur Anerkennung seiner Oberhoheit zu zwingen ", so kann ich trotz sonstiger Verschiedenheit der Ansicht meine Zustimmung zu den von mir im Druck hervorgehobenen Worten Stade's nicht stark genug betonen. Freilich, der Druck der Philister war ärger als je, d. h. nie zuvor war ihre Macht so grofs gewesen. Gelang es dem angeblichen Eroberer Abner diese starke Macht so $\mathrm{zu}$ schwächen und ihr die Ueberzeugung von Israels Unüberwindlichkeit so gründlich beizubringen, dafs er dann ruhig gegen Juda sich wenden konnte, dann ist allerdings Abner ein gar gewaltiger Kriegsheld gewesen, der die grölsten Leistungen, welche je dem Könige Saul gelungen sind, weit übertroffen hat. Um so unbegreiflicher wird dann allerdings die vollkommen feststehende Thatsache, dals Abner mit dem kleinen Juda, obgleich nach 
2 Sam. 3, 1 der Streit lange währte, nicht fertig zu werden vermochte, sondern denselben David, welchen früher Saul zur Flucht auf das Gebiet der Philister gezwungen hatte, immer stärker werden liefs.

Die Eroberer-Hypothese, welche den Abner so grofse Dinge gegen die Philister ausrichten läfst, gewinnt nun aber gar nichts, wenn wir mit Stade und wohl der grofsen Mehrzahl der neueren Ausleger den König David in Hebron als Vasallen der Philister uns denken. Reicht für die Erklärung des David als unabhängigen Fürsten die Berufung auf seine Frömmigkeit und Vaterlandsliebe schwerlich aus, um das gleichzeitige Kämpfen Abners gegen die Philister und David mit Wahrscheinlichkeit ganz auszuschliefsen, so gilt dasselbe von der Erklärung des David als blofsen Vasallenfürsten. Dazu kommt, dals der Vasall als solcher zur Heeresfolge verpflichtet ist. Wollte man sich nun auf das 1 Sam. 29 berichtete Mifstrauen der Philisterfürsten zurückziehen, welche den David am Kampfe gegen Saul nicht theilnehmen liefsen, so würde auch dies angesichts der ganz anders gewordenen Zeitumstände nichts helfen. Als die mifstrauischen Philister den David zurückschickten, stand der Judäer an der Spitze einer verhältnifsmäfsig kleinen Schaar, und die Philister fühlten sich selber zur Besiegung Sauls stark genug, und zwar mit Recht, wie der Erfolg gezeigt hat. Hatte jedoch Abner, wie die Eroberer-Hypothese annehmen mufs, die Philister bereits zu Paaren getrieben, so waren die Philister in Noth und konnten auf den Beistand ihres Vasallen David nicht verzichten, dem jetzt als dem Könige zu Hebron die volle Macht des ganzen Stammes Juda zur Verfügung stand. Die Rücksicht, welche David Saul als dem Gesalbten Jahve's oder auch seinem Freunde Jonathan als dem Nachfolger des Vaters geschuldet hätte, konnte ihn doch jetzt dem schwachen Isboseth und dem Abner gegenüber nicht mehr binden, wenn es sich um die Behauptung 
des eigenen Königthums für David handelte. Niemand wird leicht in Abrede stellen, dafs es eine Malsregel politischer Klugheit war, dafs die Philister den David König in Hebron werden liefsen. Ich glaube, dafs die Philister bei Sauls Tode so mächtig ${ }^{1}$ ) waren, dafs David nur unter Genehmigung der Philister König in Hebron werden konnte. Wer aber auch mit Köhler meint, dafs die Philister dies Königthum nicht hätten verhindern können, mufs zugestehen, dafs sie es thatsächlich nicht verhindert haben. Es unterliegt keinem Zweifel, dafs David seit seinem Uebertritt auf das philistäische Gebiet (1 Sam. 27) nicht wieder von den Philistern bekämpft worden ist, bevor er das Königthum über Gesammt-Israel annahm. Man mache sich doch klar, dals David einfach dadurch, dals er sich zum König über Juda salben liefs, die entschiedenste Gegnerschaft des Abner und Isboseth sich zuziehen mufste. Durften die Philister zu David sich dessen versehen, dals er dem Isboseth nie gutwillig weichen werde, so war für das früher (1 Sam. 29) geäufserte Mifstrauen kein Grund mehr vorhanden. Gesetzt also auch, die Philister hätten anfänglich Davids Königthum über Juda scheel angesehen, so mufste ihnen doch sehr bald die zwischen den beiden Königen der Hebräer bestehende Gegnerschaft Beruhigung gewähren. Was konnte den Philistern erwünschter sein, als dafs über die Hebräer zwei Könige gesetzt waren, die sich gegenseitig. nicht anerkannten, ja die durch langwieriges Streiten unter einander die Macht Israels gegen die Philister nur schwächen konnten? Es wird also wohl dabei bleiben, dafs die Freunde der Eroberer.Hypothese sich

1) Das nimmt auch Duncker an; aber dieser Historiker hat sich in die Eroberer-Hypothese dermafsen vertieft, dafs er meint (Gesch. des Alterthums ${ }^{5}$ II 115 Anm. 2), David sei wahrscheinlich sogar gegen Isboseth und Abner von den Philistern unterstützt worden, um Abners Fortschritten Einhalt zu thun. 
den Abner so stark denken müssen, dafs er es mit den Philistern und Judäern zusammen aufzunehmen sich getraute. So meint wirklich Stade (Gesch., S. 261), Abner habe die doppelte Aufgabe obgelegen, die an die Philister und an David verlorenen Positionen zurückzugewinnen, und der Kampf, welchen er zu diesem Zweck vom Ostjordanlande aus energisch begonnen, scheine ,zunächst ein Kampf gegen den philistäischen Lehnsmann David gewesen zu sein. " Meine Bedenken gegen dieses „zunächst" brauche ich wohl nicht auszuführen; es genügt, dals Stade's Ansicht schwerlich wahrscheinlicher ist, als die gewöhnliche Meinung, welche Ewald und Köhler vertreten.

Oben (S. 49) habe ich es einen grofsen Vortheil genannt, welchen Köhler dadurch vor Ewald voraus habe, dafs er den König David zu Hebron von den Philistern unabhängig sein läfst. Nicht nur kann Köhler viel leichter, als es für Ewald, Stade u. A. möglich ist, die schwierige Annahme vermeiden, dafs dem Abner gleichzeitig zwei Feinde gegenüberstanden, aufser David die Philister, deren Macht er zudem, was den David betrifft, nicht sehr.hoch anschlägt, sondern es gebührt jhm auch, wie mir scheint, das Lob, dafs er aus der Eroberer-Hypothese, obgleich er sich deren volle Tragweite nicht klar gemacht hat, wenigstens nach der einen Seite hin die richtige Consequenz gezogen hat. Ich übergehe den scheinbaren Widerspruch, der darin liegt, dafs nach Köhler die Philister so stark sind, dafs Abner sie erst nach langen schweren Kämpfen abschütteln kann, und zugleich so schwach, dafs sie das Königwerden Davids in Juda (II, S. 243, Anm. 5) „nicht hindern konnten.“ Fragen wir nach der grölseren geschichtlichen Wahrscheinlichkeit der beiderseitigen Hypothesen, so ist mir's nicht zweifelhaft, dafs Köhler gegen Ewald im Vortheil ist, indem er die Fortdauer des Vasallenthums, worin sich David zu Ziklag eingestandenermafsen befand, für Hebron rundweg leugnet. Nach der Eroberer-Hypothese halten that- 
sächlich beide Gelehrte, Ewald und Köhler, wie ich glaube, die Philister für viel schwächer, als es der historischen Wirklichkeit entspricht; da ist's ganz folgerichtig, dafs Köhler von dieser Schwäche der Philister auch auf ihr Verhältnifs zu David Anwendung macht. Indem er die Eroberer-Hypothese, welche im Grunde für die Schwäche der Philister, die wieder alles verlieren, Zeugnifs ablegt, geschickt für die Schwäche der Philister verwerthet, sagt Köhler a. a. O.: „Als die Aeltesten von Juda David zum Könige machten, mufsten die Philister es geschehen lassen. Denn ihre Kraft war vollständig in Anspruch genommen theils durch die gewaltsame Niederhaltung der israelitischen Bevölkerung in den Districten, welche sie infolge der Schlacht am Gilboa besetzt hielten, theils durch die Vertheidigung dieser Districte gegen die von dem Ostjordanlande aus vordringenden Anhänger Sauls, vgl. 2 Sam. 2, 8. 9." Aber wo ist denn in diesen beiden Versen über den Gang der Ausbreitung des Reiches Isboseths auch nur ein Wort zu lesen? Es ist doch nicht wunderbar, dals dem einen Hause Juda gegenüber, welches es mit David hielt, durch Aufzählung der dem Isboseth huldigenden Landschaften hervorgehoben wird, wie die Masse der Israeliten dem Hause Sauls treu blieb. Noch weniger auffällig aber ist es, nachdem in V. 8 Mahanaim erwähnt war, dals nun von dieser neuen Residenz aus die Aufzählung der Landschaften stattfand, so dafs nach dem Ostjordanlande eine Reihe westjordanischer Districte in der Folge von Norden nach Süden namhaft gemacht wurde. Exegetisch ist die Eroberer-Hypothese lediglich von anderswoher in den Text hineingetragen, ein Ergebnifs ursprünglich von blofs harmonistischer Schlufsfolgerung, dann von allerlei Erwägungen, welche der geschichtlichen Wahrscheinlichkeit zuwiderlaufen.

Wenn man dagegen, dafs David als Vasall der Philister in Hebron regierte, das Stillschweigen der Bibel über 
dies dem Patriotismus der späteren Hebräer wenig erfreuliche Verhältnifs in's Feld geführt hat, so läfst Köhler (II , 243) diesen Einwand mit Recht nicht gelten und meint : „Wenn die geschichtlichen Urkunden es auch nicht ausdrücklich berichten, so könnte es doch als Consequenz ihrer anderweitigen Angaben mit Nothwendigkeit zu folgern sein." Diese von Köhler abgelehnte Nothwendigkeit erkenne ich mit vielen neueren Auslegern, auch Stade, unbedingt an, halte es aber nicht für nöthig, die guten, für Davids Vasallenschaft geltend gemachten Gründe hier zu wiederholen, da dieselben durch Widerlegung der ErobererHypothese ohnehin eine bedeutende Verstärkung erfahren. Ich bemerke nur, dafs ich hinsichtlich 2 Sam. 8, 1 Wellhausen gegen Köhler Recht gebe, während ich in 2 Sam. 5, 17 unmöglich die Bergfeste Adullam finden kann. Da für die richtige Schätzung der Macht der Philister etwas darauf ankommt, so sei mir noch die Bemerkung gestattet, dafs m. E. die 2 Sam. 5 erwähnten grofsen Siege Davids über die Philister diesen für viele Jahrzehnte die Lust verleidet haben, noch einmal mit den Hebräern Krieg anzufangen. Nur in diesem Sinne hat David im Beginne seiner Regierung über ganz Israel die Macht der Philister gründlich gebrochen. Daher mufs ich die beiden anderen Hypothesen über das spätere Verhältnifs Davids zu den Philistern ablehnen. Weder kann ich Köhler zugeben, dafs David die Philister tributpflichtig gemacht habe, noch finde ich mit Ed. Meyer § 299 die Annahme wahrscheinlich, dafs Davids Kämpfen mit den Philistern damals „lange

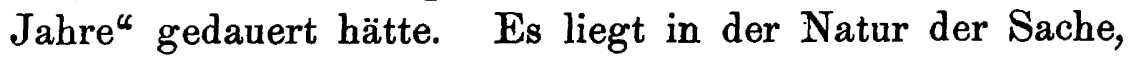
dafs einige grofse Schlachten die Frage entschieden, welche mit Davids Salbung zum Könige über Israel (2 Sam. 5, 17) von selbst gestellt war, die Frage, ob die philistäische Oberherrschaft behauptet werden würde, oder ob die Philister mit dem durch David unabhängig gewordenen Nachbarvolke in Zukunft in friedlichen Beziehungen leben sollten. 
David war viel zu klug, um das tapfere Philistervolk zum Aeufsersten treiben zu wollen; er begnügte sich mit einem für beide Theile ehrenvollen Frieden, da es ihm nur darauf ankommen konnte, die Unabhängigkeit der Hebräer dauernd sichergestellt zu sehen. Die Philister aber kannten ihren Gegner, der jetzt an der Spitze ganz Israels stand, als grolsen Kriegshelden schon lange und mufsten durch die furchtbaren Niederlagen (2 Sam. 5), auf welche Jesaja 28, 21 zurückblickt, zu der Ueberzeugung gelangen, dals es vergeblich wäre, sich noch weiter mit Israel messen zu wollen. So gründlich hat ihnen David diese Ueberzeugung beigebracht, dafs die Philister in allen folgenden Kriegen Davids nie wieder in Israel einzufallen wagten; die vereinzelten Notizen über Philisterkämpfe Davids oder seiner Helden sind daher vor 2 Sam. 5, 25 zu datiren, wenn sie nicht schon vor 1 Sam. 27, 1 fallen, vgl. Köhler II, S. 208. Uebrigens spiegelt sich die Grölse der einstigen Macht der Philister noch in diesen Notizen ab, sofern die uns erhaltenen nationalen Anekdoten es fast ausschliefslich mit Philisterkämpfen zu thun haben, wenn auch Benaja 2 Sam. 23, 20-23 mit Moabitern und einem Aegypter kämpft. Fragen wir aber, warum die grolsen Siege Davids in 2 Sam. 5 so kurz abgethan werden, so bedarf die vollkommen richtige Antwort, dafs die biblische Erzählung der politischen Geschichte überhaupt und also auch den Kriegszügen im Ganzen nur ein untergeordnetes Interesse schenkt, wohl noch einer kleinen Ergänzung, welche auf den hebräischen Nationalstolz Rücksicht nimmt. Die Philister wurden eben nicht gleich den Moabitern und andern Völkern von David unterjocht, der sich vielmehr mit einem ehrenvollen Frieden begnügte und dann so gute Beziehungen mit dem Nachbarvolke unterhielt, dafs Philister in seiner Leibwache dienten und z. B. einem Gathiter (2 Sam. 15, 19 ff.) ein wichtiger Oberbefehl von David anvertraut werden konnte. 
Nehmen wir die Rücksicht auf den hebräischen Nationalstolz zu Hülfe, so fällt der Anstof's an dem Schweigen der Bibel von Davids Vasallenthum in Hebron. Ja, dies Schweigen wird noch begreiflicher, wenn auch Isboseth zu Mahanaim in ähnlicher Abhängigkeit von den Philistern auf dem Throne safs. Erst wenn wir uns zu dieser Annahme entschliefsen, zu welcher uns schon 2 Sam. 3, 18 zu nöthigen scheint, dann schwinden alle geschichtlichen Schwierigkeiten, so dafs wir auch begreifen, warum von Philisterkriegen während der $7^{1} / 2$ Jahre nach Sauls Tod kein Wort verlautet. Mit dem angeblichen Kämpfen zwischen den Philistern und Abner fällt auch der Gedanke weg, dafs David von Hebron aus den Philistern hätte Heeresfolge gegen Israel leisten müssen. Damit wird die schon von Köhler abgelehnte Hypothese Dillmann's überflüssig, David habe sich nur verpflichtet, den Philistern im nördlichen Israel freie Hand zu lassen. Mulste David, wie Dillmann (Schenkel's Bibel-Lexikon I, 586) selbst sagt, „mit dem durch die Schlacht am Gilboa übermächtig gewordenen Philistervolke ein Abkommen treffen, wonach er von ihnen als König über Juda anerkannt wurde", so blieb er eben auch in Hebron ein Vasall der Philister, die gegen die Bemühungen Abners, Juda zur Unterwerfung unter Sauls Haus zu zwingen, natürlich nichts einzuwenden hatten. Der häusliche Zwist der Hebräer untereinander kam ja der Oberherrschaft der Philister nur zu Statten, zumal da sie das Erliegen Davids und Uebermächtigwerden des Abner nicht zu besorgen brauchten, wie der Erfolg gezeigt hat. Dafs der berühmte Philisterkämpfer David (über die von Duncker irrig bestrittene Glaubwürdigkeit von $1 \mathrm{Sam} .23$, 1-5 vgl. unten Nr. 2) den Philistern unterthänig geworden war, wenn er vielleicht auch nur geringen Tribut zahlte, das konnte ihm in den Augen der andern israelitischen Stämme nicht mehr schaden, seitdem diese in dieselbe schimpfliche Lage gerathen waren. Grade die ge- 
meinsame Dienstbarkeit wird diejenigen Israeliten, denen das Wohl des ganzen Volkes mehr am Herzen lag, als die Stammeseifersucht auf Juda, mehr und mehr veranlafst haben, ihre Blicke von dem schwachen Isboseth hinweg auf den altbewährten Bekämpfer der Philister zu richten, welchen sicherlich prophetische Stimmen als den ersehnten Befreier verkündigten; vgl. die Stellen 2 Sam. 3, 9 f. 17 f.; 5, 2, welche mit der angeblichen Salbung des David durch Samuel ja nichts zu schaffen haben, sondern eher an Gad denken lassen, den Keil zur Wahl stellt. Bei den überaus dürftigen biblischen Nachrichten kann man sich nicht ohne allerlei Vermuthungen ein anschauliches Bild davon machen, wie sogar unter anfänglich dem Judäer mifsgünstig Gesinnten der Vergleich zwischen den beiden Königen zu Mahanaim und zu Hebron immer mehr zu Gunsten Davids ausschlagen mufste. Auch ich sage mit Stade (S. 261): „Wahrlich, Sonne und Schatten waren allzu ungleich vertheilt, als dals der Ausgang des Ganzen zweifelhaft sein konnte"; aber ich kann weder von der doppelten Aufgabe des Abner reden, der sich vielmehr den Philistern unterwarf und nur gegen Juda einen lahmen, unrühmlichen Krieg führte, noch darf ich mit Stade behaupten : „Dagegen hatte David als philistäischer Lehnsmann die Hand gegen Israel nicht nur frei, sondern er stärkte mit jedem Siege über Israel sowohl seine Macht als das Vertrauen des Lehnsherrn in seine Unterwürfigkeit." Das Zusammen. fallen der beiden zuletzt genannten Stücke gilt wirklich von den 1 Sam. 27, 8-12 in durchaus glaubwürdiger Weise erzählten Streifzügen, welche David von Ziklag aus gegen räuberische Stämme unternahm, und über diesen von Wellhausen und Stade unglaubwürdig gefundenen Bericht will ich nachher in Nr. 2 mich noch näher aussprechen. Zunächst seien mir noch einige Bemerkungen über Abner und seine Zeit gestattet, damit die ErobererHypothese noch deutlicher in ihrer Nichtigkeit erkannt 
und der Vorzug des Königthums Davids vor dem des Isboseth als sehr wohl vereinbar nachgewiesen werde mit der mir feststehenden Thatsache, dafs David ohne „Siege über Israel " zur höchsten Gewalt gelangt ist.

Aus 2 Sam. 2, $8 \mathrm{f}$. erfahren wir, dals Abner, der Feldhauptmann Sauls, den Isboseth nahm ${ }^{1}$ ) und nach Mahanaim brachte und (da) zum Könige über Israel machte. Von dieser altberühmten ostjordanischen Stadt aus unternahm dann auch Abner seine Kriegszïge gegen David, von denen uns nur ein einziger (2 Sam. 2, 12-29) erzählt wird. Falsch behauptet Hengstenberg (Geschichte des Reiches Gottes unter dem Alten Bunde II, S. 115), dafs „während der ganzen sieben Jahre nur ein einziges kleines Gefecht vorfiel" ; mit Recht sagt Stade, dals nur ein einzelner Kampf, die Schlacht am Teiche zu Gibeon, uns darum erzählt werde, $₫$ weil sich an eine in ihr begangene That der Fortschritt der Handlung knüpft. “ Auch darin folgt Stade dem exegetischen Eindruck, welchen die Erzählung in 2 Sam. 2 auf jeden Unbefangenen machen mufs, dafs er Abners erstes Ausrücken ins Feld einfach der Bekämpfung Dayids gelten lälst. Sobald Abner das Abkommen mit den Philistern getroffen hatte, worin diese den Isboseth als König über das zum Hause Sauls haltende Israel unter gewissen Bedingungen anerkannten und ihm freie Hand gegen Juda liefsen, wird er wohl ohne langes Besinnen den Krieg gegen David begonnen haben. Weniger gut ist die Exegese, mit welcher Stade aus 2 Sam. 2, 8 f. folgert, „dafs Eschbaal damals noch unmündig gewesen ist - er wäre ja auch sonst mit beim Heere gewesen, welches in der Ebene Jisreel den Philistern erlag - dals er der König war, sein Grofsoheim Abner aber der eigentliche Regent. ${ }^{*}$ Da jedoch über die Hauptsache,

1) Vgl. Gen. 11, 31; 45, 18; Ex. 14, 6 f.; 2 Sam. 20, 6; Jer. 35, 3 f. u. s. w. 
die grofse Schwäche des Isboseth, volle Einigkeit besteht, so will ich nicht weiter betonen, dafs Abner (s. Riehm's HWB.) nicht der Oheim, sondern der Vetter Sauls war, und dals die Annahme von Isboseths Unmündigkeit nichts weniger als ${ }_{n}$ sicher $^{\text {" }}$ ist, wenn ich sie auch besser finde, als die Hypothese, er sei der älteste Sohn Sauls gewesen. Daraus, dafs in 1 Sam. 31 Abner und Isboseth nicht erwähnt werden, folgt weder für den einen, noch für den andern, dals er nicht „mit beim Heere gewesen"; obgleich auch Alph. Des-Vignoles (Chronologie I, p. 156) sich den Isboseth nicht in der Schlacht anwesend denkt, in welcher sein Vater und seine drei Brüder getödtet wurden, so hindert uns doch nichts an der Annahme, Saul habe seinen jüngsten Sohn der Fürsorge Abners anbefohlen. Thatsache ist, dafs Abner in der Schlacht nicht umkam. Niemand wird bezweifeln, dafs Saul seinem Feldhauptmann vor der Entscheidungsschlacht, über deren räumliche und zeitliche Ausdehnung wir nicht genauer unterrichtet sind, einen wichtigen Oberbefehl anvertraut habe. Es lassen sich allerlei Möglichkeiten für das Entrinnen des Abner und Isboseth denken. Es fällt mir nicht ein, aus Abners Entrinnen seine Feigheit zu folgern, oder aus dem Entrinnen des Isboseth, den sich Abner sicherlich nicht erst aus Gibea in Benjamin holen konnte, dessen Unmündigkeit. Der alte J. F. Buddeus (Historia ecclesiastica V. T. II, p. 124) weil's, wie noch Hengstenberg, dals allen Stämmen Israels schon bei Sauls Lebzeiten die göttliche Erwählung Davids bekannt gewesen sei, und macht dem Abner aus der Aufrichtung von Isboseths Königthum eine grofse Sünde, nebenbei auch darum, quod haud dubio sui praecipue commodi hac in re rationem habuerit. Wir brauchen den Eigennutz von Sauls Vetter nicht mit in Rechnung zu ziehen; um sein 2 Sam. 2 erzähltes Handeln begreiflich zu finden, dazu genügt, dafs er ein treuer Anhänger des Hauses Sauls war. Hengstenberg, der Ewald's 
Eroberer-Hypothese "ganz unhaltbar" nennt und sich die zwei Jahre 2 Sam. 2, 10 in der Weise des Ralbag, Grotius, Usserius, Thenius u. A. falsch so zurechtlegt, dafs Abner erst nach zweijähriger Regierung Isboseths gegen David gezogen sei, nennt den Abner einen Mann von imponirender Persönlichkeit. Allein daraus, dafs Saul diesen Vetter zu seinem Feldhauptmann machte, folgt noch nicht, dafs er ein wirklich bedeutender Mann war. Bei dem ersten grofsen Siege Sauls über die Philister und beim Amalekiterzug (1 Sam. 14 und 15) wird Abner nicht erwähnt, obgleich er schon damals Feldhauptmann sein mochte; wir wissen eben über Abners Leistungen vor Sauls Tod gar nichts, als das Selbstverständliche, dafs er den Saul auf mehreren Feldzügen begleitete, vgl. 1 Sam. 17,$55 ; 26,5 \mathrm{ff}$.

$\mathrm{Ob}$ sehr viele Wochen nach Saul's Tod vergingen, ehe die Philister den nach Mahanaim geflüchteten Isboseth, der für die israelitischen Stämme aufser Juda allein in Frage kommen konnte, als König über Israel anerkannten, oder nur wenige Wochen - wir wissen's nicht. Jedenfalls kann man nicht sagen (vgl. 1 Sam. 31,7 ff.), die Philister seien damals zur Unterwerfung des Ostjordanlandes nicht stark genug gewesen. Mir ist's nicht unwahrscheinlich, dafs die beiden Könige Isboseth und David gleichzeitig von den Philistern als Vasallenkönige anerkannt worden sind; die Frage, wie lange die solchem Abkummen vorhergehenden Verhandlungen gedauert haben, hat um so weniger Interesse, als es nicht unwahrscheinlich ist, dafs recht bald sowohl Abner für Isboseth, als auch David in Hebron den Philistern entgegengekommen sind mit Bezeugung ihrer Anerkennung einer philistäischen Oberherrschaft. Merkwürdig mufs es uns erscheinen, dafs Mahanaim nicht nur zum ersten Sitz des Isboseth erwählt wurde, sondern auch immer, so viel wir wissen (vgl. 2 Sam. 4, 7 f. mit 2, 29), die Residenz desselben geblieben 
ist. Wie will man dies Verbleiben der Wohnung Isboseths in Mahanaim mit der Eroberer-Hypothese in einen irgend wahrscheinlichen Einklang bringen? Höchstens für die erste Zeit nach Sauls Tod könnte man mit Stade (Gesch. S. 261) meinen : „Dafs Abner den Sitz der Regierung in die altisraelitischen Gaue jenseit des Jordans verlegte, war ein vernünftiger Entschlufs, denn dort lag unter den jetzigen Verhältnissen der Schwerpunkt des Volkslebens." Ich finde das Bleiben des Regierungssitzes im Ostjordanlande, welches der Eroberungshypothese wenig entspricht, so auffällig, dafs mir der Gedanke an die Furcht des schwachen Isboseth vor den Philistern kaum ausreicht, ich vielmehr annehmen möchte, dafs die Philister zu ihrer gröfseren Sicherheit die Bedingung gestellt haben, dals Isboseth in dem fernen und den Angriffen der ostjordanischen Völker leicht ausgesetzten Gebiet verbleiben solle.

Obgleich ich die Wahrheit der von mir angenommenen Thatsache, dafs Isboseth nur durch Tributzahlung an die Philister auf seinem Throne safs, durch die geschichtliche Gesammtlage hinreichend gestützt glaube und einer aus Israels Verhältnifs zu Moab abgeleiteten Hülfshypothese in keiner Weise bedarf, will ich diese Nebenvermuthung doch schon darum erwähnen, weil sie von völlig unverdächtiger Seite her kommt, nämlich von Ewald, dem Hauptbegründer der von mir bekämpften Eroberer-Hypothese, vgl. Gesch. ${ }^{3}$ III, 203. Ohne Zweifel hatte Saul die Ammoniter und Moabiter seine starke Hand schwer fühlen lassen (1 Sam. $11 ; 14,47)$. Naturgemäls werden wir erwarten, dals diese Feinde Sauls dem von Saul so hart bedrängten David freundlich gesinnt waren, wenn wir auch die geschichtswidrige Meinung, dals David als Empörer seinen König bekriegt habe, noch so entschieden verwerfen. Die genannte Erwartung wird auch ausdrücklich bestätigt, was die Ammoniter betrifft, durch die Notiz 2 Sam. 10, 2, dals König Nahas dem David Freundlichkeit 
erwiesen hatte, für die Moabiter durch die eben so glaubwürdige ${ }^{1}$ ) Nachricht 1 Sam. 22, 3 f., wonach der vor Saul flüchtige David seine Eltern dem Schutz der Moabiter anvertraute, so dafs wir uns auf die Abstammung von der Moabiterin Ruth nicht einmal zu berufen brauchen. Wie auffallend nun, dals David als König über Gesammt-Israel so früh, wahrscheinlich sehr bald, nachdem er die Philister zur Ruhe gebracht hat, die Moabiter mit Krieg überzieht und die Besiegten so ungewöhnlich hart straft (2 Sam. 8, 2)! Alle Ausleger sind darüber einig, dafs die Moabiter den Zorn der Israeliten empfindlich gereizt haben müssen. Von den Ammonitern wird uns eine starke Reizung in 2 Sam. 10 ausdrücklich gemeldet. $\mathrm{Da}$ Ewald den mehrjährigen Ammoniterkrieg gewifs mit Recht später setzt als den Moabiterkrieg Davids, den Ammonitern also die harte Bestrafung Moabs schon bekannt sein mufste, so mag man sich über das Wagnifs der in 2 Sam. 10 erzählten Reizung billig wundern und auf den Gedanken kommen, Israel

1) Stade (Gesch. S. 236, Anm. 2) leugnet dies, weil in der Mittheilung 1 Sam. 22, 1, áuf die Kunde ron Davids Entrinnen nach Adullam sei "das ganze Haus seines Vaters" mit seinen Brüdern dahingekommen, vorausgesetzt werde, dafs Davids Eltern bereits gestorben waren, und bezeichnet Vers 3. 4 als einen mit Vers 1 in Widerspruch stehenden späteren Einschub. Eben so gut könnte man mit Wellhausen (Text der Bücher Samuelis, S. 124) aus 1 Sam. 20, 29, wonach David durch einen seiner Brüder persönlich (LXX erleichternd : durch seine Brüder) zum Opferfest eingeladen wird, auf bereits eingetretenen Tod der Eltern schliefsen. Allerdings war David des Isai jüngster Sohn. Da aber der Zeitraum zwischen Davids Kommen an den Hof des Saul und seiner Flucht nicht viele Jahre betrug, konnten die Eltern damals sehr gut noch leben, während sie allerdings zu alt waren, um das bevorstehende Fluchtleben ihres Sohnes mitzumachen. Was Wellhausen sonst noch zu Gunsten seiner Behauptung, dafs Vers 3. 4 schwerlich dem ursprtinglichen Zusammenhange angehören ${ }^{*}$, angeführt hat, halte ich für eben so wenig beweiskräftig. Davids Fürsorge für seine betagten Eltern empfiehlt sich durch ihre innere Wahrscheinlichkeit, vgl. Köhler II, S. 209. 
müsse dem Hanun wohl Veranlassung zu solcher Geringschätzung gegeben haben. Doch ich lege anf diesen Gedanken zunächst noch kein Gewicht, da das Handeln des morgenländischen Selbstherrschers, dessen Uebermuth sich zudem auf starke Bundesgenossen verlassen konnte, leicht unberechenbar erscheint. Nur darauf sei kurz hingewiesen, dal's 2 Sam. 10, 3 f. durchaus den Eindruck macht, dafs Hanun nicht nach eigener Laune, sondern im Einverständnils mit seinem Hofe handelte. Sehr wichtig aber ist's, dal's die Moabiter sich eine mindestens eben so geringschätzige Behandlung Israels erlaubt zu haben scheinen. Es liegt ja auf der Hand, dafs nach der richtigen Auffassung von 2 Sam. 12, 31, welche ich an einem anderen Orte (vgl. die Nachweisung in dieser Zeitschrift 188.5, S. 187) zu vertheidigen suchte, die Strafe der Ammoniter lange nicht so hart ausfiel, als diejenige der Moabiter. Wir werden dadurch zu der Vermuthung gedrängt, dafs die von Moab dem israelitischen Nationalgefühl zugefügte Kränkung über das 2 Sam. 10 berichtete Beschimpfen der Gesandten Davids noch weit hinausgegangen sein wird. Nach der höchst ansprechenden Vermuthung Ewald's „hatte vielleicht Isbóshet der in der nähe 'Ammôn's und Moab's seinen siz nahm die freundschaft mit Moab unter schimptlichen bedingungen erhalten welche David nicht eingehen wollte." Ist dem wirklich so, dann begreift sich, dals David, der als König über ganz Israel den mächtigen Philistern keinen Tribut mehr zahlte, noch viel weniger dem kleinen Moab gegenüber mit Sendung der schimpflich genug von Isboseth und Abner bewilligten Geschenke fortfahren konnte. Ganz sicher ist's, dafs die Moabiter, die gerade von David mehr Entgegenkommen erwartet haben mochten, den Israeliten die äufserste Verachtung gezeigt, ihren Zorn auf's höchste gereizt haben müssen, so dals man nach 1 Sam. 11, 2 daran denken könnte, sie hätten wirklich den israelitischen Gesandten das rechte 
Auge ausgestochen. Wollte man mir aber einwenden, dals ich mich in ein Gewirre von Hypothesen verliere, so würde ich auf das hier thatsächlich vorliegende geschichtliche Räthsel verweisen, welches darin besteht, dafs die Moabiter und die Ammoniter sich veranlalst gesehen haben, den Israeliten mit äufserster Geringschätzung zu begegnen. Diese Verachtung Israels durch die beiden ostjordanischen Völker, welche der Eroberer-Hypothese schnurstracks zuwiderläuft, bedarf der Erklärung. Natürlich kann eine solche nur vermuthungsweise gegeben werden. Da man aber den Moabitern und Ammonitern kein unsinniges Wagnifs zuschreiben darf, so mufs die Lage der Israeliten unter Abner und Isboseth wirklich eine schimpfliche gewesen sein, wie dies Ewald's Scharfsinn im Widerspruch mit seiner sonstigen Annahme von Abners vermeintlichen Grofsthaten richtig erkannt hat. War Israels Ansehen, wie ich glaube annehmen zu müssen, damals so tief gesunken, dann begreift es sich leicht, dafs Moab und Ammon sich über die Leistungsfähigkeit Davids, der das bisherige Israel nur um einen Stamm zu verstärken schien, so schwer täuschen konnten. Zudem fiel die schwerste Kränkung Israels, welche die Moabiter sich erlaubten, wahrscheinlich in dieselbe Zeit, als David seine ganze Kraft aufbieten mulste, um die Entscheidungsschlachten gegen die Philister siegreich zu bestehen. Erst David hat das Nationalgefühl der Israeliten wieder gehoben, welche die tiefe Schmach Israels unter Isboseth und Abner dann gerne vergessen haben.

Ist das Bild, welches ich mir auf Grund der angegebenen geschichtlichen Erwägungen von der unrühmlichen Lage Israels unter Isboseth entworfen habe, auch nur im Grofsen und Ganzen richtig, so springt der Vorzug des Königs David zu Hebron in die Augen. Zwar mufste auch Juda die unvermeidliche Abgabe an die Philister entrichten; dafür genofs aber das Ländchen unter Davids 
starkem Schutz gewifs eine auggezeichnete Regierung, eine bessere, als in den letzten schlimmen Zeiten von Sauls Regiment uberhaupt møglich war. Hatte David in versteckter Weise schon von Ziklag aus seinen Stammgenossen Schutz und Hulfe gegen räuberische Beduinen gewährt, so konnte er diesem Geschäft als Konnig mit seinen tapferen Kriegern offen und ehrenvoll obliegen, vgl. 2 Sam. 3, 22. Dafs David unter schimpflichen Bedingungen sich mit den Beduinen abgefunden haben sollte, ist geschichtlich ebenso undenkbar, wie die wunderliche Meinung von Hengstenberg (Gesch. II, S. 89) u. A., der tapfere König Saul habe sich im Beginn seiner Regierung eine Entwaffnung durch die Philister gefallen lassen. Während David so seinen Kriegsruhm mehrte in glücklicher Bekämpfung fremder Stämme, natürlich mit schuldiger Rücksicht auf die mächtigen Philister, deren Verletzung ja die gröliste Thorheit gewesen wäre, war Abner nicht nur gecren die Philister unterwürfig, sondern liefs sich wohl auch im (Jstjordanlande Schimpfliches bieten, um nur die Hand frei gegen David zu haben. Psychologisch ist es leicht begreiflich, wenn bei Isboseth und Abner das dynastische Interesse und die Eifersucht der Benjaminiter gegen Juda die Rücksicht auf das allgemeine Beste überwog. Mul'ste doch jedenfalls Tribut gegeben werden, was lag dann viel daran, wenn man sich auch einmal durch kleinere (teschenke vor einem moabitischen oder ammonitischen Ueberfall sicherstellte? Wie später Rezin und Pekah durch die Eroberung Judas sich gegen Assur zu stärken hofften, so konnte Abner sich einreden, wenn erst die granze Kraft Israels und Juda's ') in seiner Hand vereinigt sei, werde

1) Ohne alle Unterschatzung der Macht Juda's halte ich es für unstatthaft, wenn Stade (Gesch., 8. 265) von dor Aussicht auf die durch die Vereinigung mit Juda zu gewinnende Starkung behauptet : ${ }_{n}$ Sio war es ja doch, welche don Adelegeschlechtern Josephs und Benjamins den Judker David als König überhaupt erträglich machte.“ 
es ihm schon an einer günstigen Gelegenheit zur Abrechnung mit den Philistern nicht fehlen. In dieser Weise erklären sich Abners Kriegszüge gegen Juda, die einzigen kriegerischen Unternehmungen Abners in der Zeit nach Sauls Tode, von welchen wir überhaupt geschichtliche, wenn auch recht dürftige Kunde besitzen. In die anschauliche Erzählung 2 Sam. 2, 12-3, 1 haben sich sagenhafte Züge eingeschlichen. Keineswegs aber möchte ich mit Stade (Gesch., S. 262) behaupten, dafs diese Nachricht von der Schlacht beim Teiche zu Gibeon durchaus sagenhafter Natur sei. Giebt doch Stade selbst zu, dafs sich an die That der Tödtung des Asahel durch Abner „der Fortschritt der Handlung knüpft", während z. B. der sicher ungeschichtliche erste Aufenthalt Davids bei Achis (Stade, Gesch., S. 240) „ein den Zusammenhang plump unterbrechender anekdotenartiger Einschub" (1 Sam.21, 11-16) genannt werden darf, schon weil er ohne alle geschichtlichen Folgen bleibt. Mag man der etymologischen Localsage 2 Sam. 2, 16 auch allen historischen Werth absprechen müssen, so wäre es doch m. E. unrichtig zu behaupten, dafs wir von den Kämpfen zwischen Isboseth und David durchaus nichts Sicheres wülsten.

Folgende drei Punkte können, ohne dals wir auf alle Einzelheiten eingehen, für die Kämpfe Abners mit David als sicher gelten. Erstens hat nicht nur das spätere Israel die unrühmlichen Bruderkämpfe gern vergessen, sondern schon die Zeitgenossen hatten deutlich das Gefühl (vgl. 2 Sam. 2, 26. 27), dafs dieser Krieg ein Bruderkrieg sei. Das ist aufserordentlich wichtig, weil die Verehrung Jahve's, je aufrichtiger und lebendiger sie war, desto stärker den Bruderkrieg als solchen verabscheuen mufste. Eine Zeit,

Vielleicht aber denkt Stade bei der "Vereinigung mit Juda“ in erster Linie an die Anerkennung der gewaltigen Person Davids, so dals mein Bedenken sich exledigt. Uebrigens vgl. 2 Sam. 3, $17 \mathrm{ff}$. 
in der das ganze Lebenswerk des Saul vernichtet und Jahre sein Volk zürnend in die Hand der Heiden gegeben zu haben schien, war eine Zeit der Noth, welche das religiöse Gefühl Israels mächtig anfachen mulste; damit aber ist eine irgend tief gehende Stimmung des Volks zu Gunsten des brudermörderischen Kriegs schlechterdings unvereinbar ${ }^{1}$ ), mag man sich die politische Eifersucht mancher Volkshäupter auf Juda auch noch so grofs vorstellen. Zweitens wurden die Kämpfe, wenn ich mich des Ausdrucks bedienen darf, durch die Berufssoldaten oder das stehende Heer, nicht durch das nach Art des Landsturms aufgebotene Volk selbst geführt. Mit Ed. Reufs erblicke ich in der Kleinheit der in 2 Sam. 2 für die beiderseitigen Krieger angegebenen Zahlen einen Beweis der wesentlichen Geschichtlichkeit des Berichts, so dals ich Köhler's textwidrige Vermuthung, Abner habe diesen Zug nur zur Vorbereitung des gegen David geplanten Krieges unternommen, als eine höchst unwahrscheinliche ablehnen mufs. Wir dürfen uns keine übertriebene Vorstellung von den Kämpfen zwischen den Truppen der beiden hebräischen Könige machen, von dem Streit, wie es 2 Sam. 3, 1. 6 heifst, zwischen dem Hause Sauls und dem Hause Davids. Obgleich es nicht zu grolsen Schlachten kam, hat der Krieg gegen 7 Jahre gedauert, mag ihn auch Abner je länger, desto lahmer, weil aussichtsloser, geführt haben. Nachdem das Treffen bei Gibeon beendigt ist, kehrt

1) Wer von der israelitischen Religion eine so niedrige Vorstellung hat wie Ed. Meyer (I, § 309), mit diesem Gelehrten möglich findet (I, S. 351), dafs dem Stamme Juda vielleicht hebräische Elemente ganz fehlten, und weifs, dafs der Usurpator David alle Nachkommen Sauls bis auf einen lahmen Sohn Jonathans umbringen liefs, der mag es für wissenschaftlich halten zu sagen (I, § 306) : „Davids Krieg gegen Išba'al batte die kaum vollzogene Einigung zwischen Israel und Juda wieder aufgehoben; und Davids Erhebung zum Könige mufste den nördlichen Stämmen als Fremdherrschaft erscheinen." 
Abner, der vielleicht mit dreitausend Mann ausgerückt war, nach Hause zurück, Joab seinerseits natürlich dann auch; die Sache war für diesmal zu Ende, um im nächsten Jahre wieder zu beginnen. Dafs sich Davids Leute, die oft genug Streifzüge südwärts machten, doch nicht von Abner überraschen lielsen, dafür zeugt die nördliche Lage von Gibeon. Drittens muls als sicher gelten, dals der Angriff von Seiten des Isboseth und Abner ausging, während David sich lediglich vertheidigte, so dals er das Gehässige des in immer weiteren Kreisen als unnütz anerkannten und verabscheuten Bruderkriegs, der nie Sache des eigentlichen Volks gewesen war, ganz der Gegenseite überliefs. Hätten wir nicht einmal den Bericht über das Treffen bei Gibeon, so würde sich doch dieser dritte Punkt ganz von selbst verstehen für jeden, der dem David auch nur ein wenig Klugheit zutraut. David mufste und wollte ruhig den Gang der Dinge abwarten, d. h., wie wir religiös uns ausdrücken würden, die Zukunft seinem Gott anheimstellen. Aber er konnte auch ruhig warten, da die Dinge, wie wir gesehen haben, für ihn so günstig lagen, dafs er immer stärker, das Haus Saul's immer schwächer wurde. Alsbald nach dem Tode des Saul und seiner streitbaren Söhne konnte dem die geschichtlichen Verhältnisse klar genug durchschauenden David die Aussicht nicht entgehen, welche sich jetzt ihm eröffnete, die Hoffnung auf das Königthum über ganz Israel. Schon um der Philister willen liefs sich diese hohe Stellung nicht gewaltsam gewinnen. David wird früh genug gewufst haben, dafs Isboseth der hohen Aufgabe des Königs über Israel nicht von ferne gewachsen war, und dafs auch der in seiner Art tapfere. und dem Hause Sauls treu ergebene Abner die Mängel seines Herrn nicht ersetzen konnte. Ehe noch Abner den schwachen Isboseth aufgab, wünschten sich die Einsichtigen unter den Aeltesten Israels den David zum König, wie aus 2 Sam. 3, 17 deutlich erhellt. Stade sagt sehr 
wahr : „Trotz des Selbständigkeitstriebes der einzelnen Stämme würde David schliefslich Alleinherrscher geworden sein. Dafs er es so schnell wurde, verdankte er der Uneinigkeit im Lager der Feinde." Gewifs, die Kapitel 2 Sam. 2-5 (Stade, Gesch. S. 260) $\pi^{8 c h i l d e r n ~ u n s ~ s e h r ~}$ anschaulich, wie Davids Macht von Stufe zu Stufe sich theils durch die eigene Kraft und die eigene Klugheit, theils durch die (Ohnmacht, Unklugheit und Schlechtigkeit der Gregner hebt", oder, dafs ich Wellhausen (Bleek ${ }^{4} 222$ )

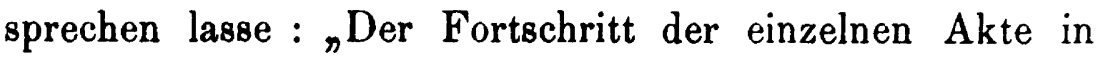
c. 2-5 ist von beinah drastischer Consequenz, Stufe für Stufe werden wir über die Hindernisse hinweg bis zur Höhe fortgeführt." Irre ich mich nicht, so wird dieser von Gott so wunderbar geleitete Fortschritt der Geschichte, in welchem David ohne alle nachweisbare Verschuldung blieb, durch Hinwegräumung der unhaltbaren ErobererHypothese noch viel klarer und schöner erkannte.

2. Nach der etwas ausführlich gewordenen Besprechung der Eroberer-Hypothese mögen kürzere Besprechungen von 1 Sam. 23, 1-j und 27, 8-12 diese Mittheilungen abschliefsen. Ich wähle die erwähnten beiden Stellen, deren geschichtlicher Werth stark angefochten ist, darum aus, weil sie für die richtige Würdigung von Davids Charakter nicht ohne Interesse sind. Ewald (Gesch. ${ }^{3}$ III, $123 \mathrm{ff.} \mathrm{141)} \mathrm{findet} \mathrm{beides} \mathrm{glaubwürdig,} \mathrm{sowohl} \mathrm{dafs} \mathrm{David}$ als Freibeuter an den Grenzen Juda's die Stadt Kegila von den Philistern, denen er eine grofse Niederlage beibrachte, befreit habe, als auch, dals David als philistäischer Lehnsträger von Ziklag aus in grausamer Weise Beduinenstämme bekriegt und durch wiederholte Lügen bei dem Könige Achis von Gath die für die Treue des Vasallen günstige Meinung hervorgerufen habe, dafs in Wirklichkeit Davids Beutezüge nur judäischen Landsleuten oder Schutzgenossen gälten. Duncker erklärt beide Erzählungen für unglaubwürdig; Wellhausen und Stade 
wollen den Entsatz von Kegila, welchen uns die in der Mitte des hebräischen Samuelsbuches benutzte und sehr werthvolle alte Davidsgeschichte erzählt, als Thatsache anerkennen, betrachten aber die doch derselben alten Quelle angehörige Nachricht über Davids die Philister täuschenden Streifzüge wegen angeblicher innerer Unwahrscheinlichkeit als ein Einschiebsel ohne historische Glaubwürdigkeit. Mich wundert's fast, dafs 1 Sam. 23, 1-5 am wenigsten bestritten wird, da mir die Bedenken gegen diesen Bericht viel eher Eindruck machen würden, als die gegen den andern. Obwohl ich aber hier Wellhausen und Stade auf meiner Seite habe, so kann ich ein näheres Eingehen auf Duncker's Angriff doch nicht für überflüssig halten.

Die von Duncker ( ${ }^{5} \mathrm{II}, 108$, Anm. 3) gegen 1 Sam. 23, 1-5 vorgebrachten Gründe sind diese drei oder vier, deren Zählung von mir herrührt, während ich im Uebrigen wörtlich citire : „Dals David Kegila vor den Philistern gerettet und dadurch gewonnen, dafs er einen grofsen Sieg über diese errungen, ist mehr als unwahrscheinlich. 1) David konnte es sicherlich nicht unternehmen, mit 600 Mann gegen Saul und die Philister zugleich zu kämpfen. 2) Wie hätte er einem Heer der Philister im Felde begegnen mögen, da er sich nicht einmal getraut, mit seiner Schaar die Mauern Kegila's gegen Saul zu halten. 3) Auch wären die Bürger Kegila's schwerlich von vornherein bereit gewesen, ihn auszuliefern, wenn er ihnen kurz zuvor eine so grofse Wohlthat erwiesen hätte. 4) Endlich widerspricht solcher Kampf gegen die Philister auf das stärkste dem Verhältnils, in welchem wir David vorher und nachher zu den Philistern finden. Achis wenigstens hat seit seinem Uebergang unbedingtes Vertrauen zu David und will ihn sogar zum Hüter seines Hauptes setzen, 1 Sam. 28, 2.“ Erst nachdem Wellhausen eine schärfere Scheidung der Quellen gelungen ist, darf man allgemeine Zustimmung zu seinem 
Urtheil (Skizzen I, S. 27) verlangen : „Es ist unberechtigt, David für den Untergang Sauls, zu dem er sich mit der Hierokratie verbündet habe, verantwortlich zu machen." In der letzten Bearbeitung seines Werkes hält Duncker den David noch für einen Empörer gegen Saul, nicht für einen unschuldig $\left.{ }^{1}\right)$ Verfolgten, und zeichnet ein abstofsendes Zerrbild von David, nicht auf Grund der geschichtlichen Quellen, welche bekanntlich die wirklichen Schwächen Davids an manchen Stellen offen blofslegen, sondern aus blofsem Mifsverständnifs und aus vorgefalster Meinung heraus. Der Widerwille des Historikers gegen ndie Kanonisirung Davids durch die spätjüdische Tradition, die einen levitischen Heiligen aus ihm gemacht hat", wie Wellhausen sich treffend ausdrückt, macht sich auch bei Duncker geltend, wenn er z. B. S. 116 auf die nichtigsten

1) Die Möglichkeit will ich nicht leugnen, dafs David sich wohl einmal über seinen Schwiegervater respectwidrig geăufsert, und dafs solche Reden, von Davids Neidern dem kranken König hiuterbracht, diesen gereizt haben. Unschuldig nenne ich David, weil es nur ein Wahn des Saul war, dafs sein Eidam auf seine Entthronung sinne, eine fixe Idee, welche bei der Eifersucht und dem Argwohn des kranken Mannes doch wahrlich begreiflich genug ist, so dafs es der Hypothese von Stade (Gesch. S. 241 f.) nicht bedarf. Wäre dem David und den Eliden zu Nob auch der Gedanke gekommen, wie schön es sein würde, wollte Saul sich zu seinen Vätern schlafen legen und den viel geigneteren Jonathan Platz machen, so hätten sie doch unmöglich daran denken können, eine Thron-Entsetzung zu Gunsten Jonathans zu bewirken. Solche Wünsche hätten, von dem grolsen Ansehen Sauls beim Volk noch zu schweigen, an der Person des Jonathan scheitern müssen. Ueberdies war die Entthronung des Königs obne seine Ermordung nicht denkbar; ein Mann wie Saul dankt nicht freiwillig ab. Sogar Ferd. Justi (Gesch. der orientalischen Völker im Altertum. Berlin 1884, S. 281), der Sauls Verdacht, David strebe nach dem Thron, zu meiner nicht geringen Verwunderung gerechtfertigt findet, folgt der biblischen Darstellung von der Entstehung der Feindschaft des Königs, indem er sagt : ${ }_{n}$ Doch erweckten diese Erfolge in Sauls Seele Mifsgunst und den Gedanken, dafs David seiner Stellung gefährlich werden und sich selbst an die Spitze stellen könnte." 
Gründe hin den David als elendesten Heuchler schildert, indem er ihm die Ermordung Abners, in die Schuhe schiebt." Unter solchen Umständen wundert es mich nicht, dafs Duncker in dem Streben nach historischer Wahrheit die ärgsten Mifsgriffe begehen konnte. Gewifs hat er Recht, wenn er S. 106 behauptet : „Selbst die vollste Anerkennung für das, was David später für Israel und über Israel weit hinaus wirkend gegründet hat, verpflichtet doch nicht, die Wege zu übersehen, auf denen er emporgestiegen ist." Ich kann nur die gründlichste Untersuchung dieser Wege wünschen, damit an die Stelle der noch so vielfach uns begegnenden Widersprüche und baaren Unmöglichkeiten mehr und mehr die geschichtliche Wahrscheinlichkeit trete. Ich habe auf Grund der Quellen die Ansicht, dafs David auch nach seiner Flucht von Sauls Hofe die Philister noch bekämpft hat, und erfreue mich dabei, wie gesagt, der Zustimmung Stade's (Gesch., S. 244), der 1 Sam. 23, 1 ff. für geschichtlich hält. Grade so wichtig ist aber in meinen Augen die von Stade bestrittene Thatsache, dafs David niemals einen Angriffskrieg gegen seine israelitischen Landsleute geführt hat. Wie bestimmt aber Stade dies leugnet, zeigen die Worte, mit denen er den richtigen Nachweis, dals Davids Erhebung zum Könige über ganz Israel die Abschüttlung seines bisherigen Lehnsverhältnisses bedeutet, zu Ende führt : „Gar manches in Davids Leben mufste der Vergessenheit anheimfallen und konnte es nur dadurch, dafs er die Aufgabe glücklich löste, an welcher Saul mit den Seinigen gescheitert war. Er, der sich seinen besten Ruhm in den unter Sauls Regierung geschlagenen Schlachten gegen die Philister erworben hatte, sehnte wohl schon lange den Augenblick herbei, welcher ihm gestatten würde, die besseren Traditionen seiner Jugend wieder aufzunehmen."

Bekanntlich kam David als bewährter Krieger in Sauls Nähe und erwarb sich dann in weiteren Kämpfen 
mit dem Erbfeinde seines Volkes als Diener Sauls den grofsten Ruhm. Mit Recht feierte Israel den hocherhabenen Kriegsobersten als unbesiegten Helden und als Schrecken der verhafsten Philister. Plötzlich mulste David vom Hofe seines Königs, der ihm, von unheilbarem Wahn verblendet, das Leben nehmen wollte, wie ein Hochverräther fliehen, Alles im Stich lassend. Auf den Schutz Jahve's, der dem Unschuldigen hilft, auf die Freundschaft Jonathans, dessen mit der Zeit erhoffte Thronbesteigung ihm nur ehrenvolle Zurückrufung verschaffen konnte (Stade, S. 242), auf seine eigene Tüchtigkeit und Findigkeit mulste sich nun David verlassen während der schlimmen Zeit, welche er als Freibeuter und Bandenführer an den Grenzen Juda's zubrachte, häufig von Saul verfolgt, doch nicht der Sefshaftigkeit ganz entbehrend (vgl. 1 Sam. 25, 14 ff.), und während der noch schlimmeren, aber wohl kürzeren Zeit, in welcher er als Vasall der Philister bis zu Sauls Tod deren Schutz genols. Ich zweifle nicht, dal's die Besiegung der Philister bei Kegila ziemlich in den Anfang des mehrere Jahre dauernden Freibeuterlebens fällt, nachdem sich eine Schaar von tapferen Kriegern um den gefeierten Helden gesammelt hatte, nicht nur Verwandte und Freunde, die sein Geschick theilen wollten, sondern auch allerlei kecke Gesellen, die nichts zu verlieren hatten oder der ihnen mifsliebig gewordenen Heimath das abenteuernde Leben unter dem Befehl des berühmten Kriegsobersten vorzogen. Die Einrechnung in den Anfang des Freibeuterlebens entspricht nicht nur der Stellung des Berichts, sondern folgt auch aus der Natur der Sache. David hat schwerlich die verwegene Hoffnung gehegt, er könne sich (vgl. Stade, S. 243) in einem Grenzgebiete von unklarer staatlicher Stellung ein kleines, von Israel wie den Philistern unabhängiges Fürstenthum errichten, hat überhaupt nicht an ein Fürstenthum für sich gedacht, sondern war froh, wenn er sich anständig mit seinen Leuten durch's 
Leben schlagen konnte, ohne dem Saul oder den Philistern in die Hände zu fallen. Während die Sage den David im Anfang seiner Flucht zum Philisterkönig Achis fliehen und mit genauer Noth wieder entrinnen läfst und Duncker (S. 107) sogar nicht bezweifelt, dals das schönste Einverständnifs zwischen dem von Saul abtrünnigen David und den Philistern bestand, wie denn David von Ziklag aus (S. 110) „den kleinen Krieg gegen Saul und sein Vaterland" geführt haben soll, lehrt vielmehr die wirkliche Geschichte gerade umgekehrt, dafs David trotz der von Saul unzweifelhaft ihm drohenden Gefahr gegen die Philister, Sauls Feinde, feindselig aufgetreten ist. Mufs das nicht als der Gipfel der Thorheit erscheinen?

Die Bedenken Duncker's begreifen sich leicht; wenn ihm auch der vierte Grund oder die Voraussetzung, dafs David sich freundlich zu den Philistern stellen mufste, das Ausschlaggebende ist, so stellt er doch als ersten Grund die Unmöglichkeit voran, dals David gleichzeitig gegen Saul und die Philister kämpfen konnte. Offenbar wiegen ihm das zweite und dritte Bedenken weniger schwer. Die Möglichkeit, dals eine gut geführte, verwegene kleinere Schaar von Kerntruppen über ein gröfseres Heer in offenem Felde den Sieg davon trägt, wird wohl Niemand leugnen. $\mathrm{Zu}$ grofs brauchen wir uns das gegen Kegila ausgerückte Philisterheer auch nicht zu denken. Dazu kommt nicht nur die Theilung der Philister in solche, welche Kegila belagerten, und andere, die in der Umgegend mit Plündern beschäftigt waren, sondern auch die völlige Ueberraschung der Philister, die den Saul ferne wufsten und sich des Ueberfalls durch David nicht versahen. Auch der Umstand macht keine Schwierigkeit, dafs David auf die Kunde hin, dafs Saul grofse Rüstungen betrieb, sich nicht ohne Weiteres auf die Dankbarkeit der Bürger von Kegila verlassen mochte. Kam Saul mit dem Heerbanne Israels, so konnte er die Stadt leicht verderben, wenn sie ihm nicht 
der Eigennutz der Belagerten oder auch nur einiger weniger Bürger, die zum Verrath schon hinreichten, bald in die Hände spielte. Vielleicht hatte David schon gemerkt, dafs sein Haufe den Bürgern der kleinen Festung zum Theil unbequem war. Wie albern es auch wäre, sich den David in seiner damaligen Lage als richtigen Räuberhauptmann vorzustellen, so ist's doch wohl eine selbstverständliche Annahme, wenn wir an die zweifelhaften Elemente unter Landsknechten oder Fremdenlegionen uns erinnern, dafs es unter der Bande Davids lose Gesellen gab, denen der friedliche Bürger lieber auf den Rücken sah, als dafs er sie auf unbestimmte Dauer bei sich beherbergt hätte. Die Schilderung, welche unsere alte Quelle von Davids Haufen in $1 \mathrm{Sam} .22,2$ giebt, belehrt uns darïber deutlich genug; vgl. auch 1 Sam. 25, 10, wo das Wort des groben Nabal die Meinung manchen Spiefsbürgers ausdrücken mag. Noch deutlicher ergiebt sich die Gefährlichkeit der Bande vielleicht aus der Lebensgefahr (1 Sam. 30,6), in welcher David selber durch sie sich befinden konnte, und zwar in einer Zeit, da die Leute doch schon lange unter dem disciplinirenden Einflufs Davids gestanden hatten. Hätte David nicht ernstlichen Anlals zu der Sorge gehabt, dafs ihm Verrath drohe, wenn er die Einschliefsung Kegila's durch Sauls grofses Heer abwarte, so würde er das Orakel nicht befragt haben. Da das Orakel ${ }^{1}$ ) das Bedenken des David und vielleicht auch

1) Die vier ersten Wörter von 1 Sam. 23, 11 und die drei letzten von Vs. 12 schildern m. E. den wirklichen Hergang und enthalten den ursprünglichen Bericht, so dafs das Dazwischenstehende als überflüssig für uns wegfällt, wenn es auch schon in der Quellenschrift stand. Da ja David, der durch seine Freunde gut bedient wurde, die Nachricht von Sauls Absicht empfangen hatte, so brauchte er das Orakel nicht mehr zu fragen, ob Saul kommen werde. Dem David in Kegila genügte die eine Frage; um so wichtiger sind die beiden Fragen, ehe David sich zum Zuge nach Kegila entschlors. 
seiner Leute bestätigte, so zogen sie natürlich aus Kegila ab. Kurz, der zweite und dritte Grund, worauf Duncker sich beruft, machen keine Schwierigkeit. Das wirklich schwerwiegende Bedenken ist die Nothwendigkeit, welche mit der Geschichtlichkeit von 1 Sam. 23, 1-5 gegeben zu sein scheint, dafs David sich zu der in sicherer Aussicht stehenden Verfolgung durch Saul fast muthwillig obendrein die Feindschaft der Philister auf den Hals geladen haben würde, vgl. 1 Sam. 23, 3.

Prüfen wir nun dies Bedenken, so läfst sich der genannte Schein leicht in seiner Nichtigkeit für den tiefer Blickenden erkennen. Dabei ist's weder nöthig, noch rathsam, dals wir annehmen, David habe den tieferen Blick damals schon in dem vollen Malse besessen, wie ihn erst die spätere Entwicklung der Dinge möglich machte. Der von Gott geleitete geschichtliche Verlauf hat Davids Zug gegen die Philister als ein ebenso kluges als frommes Unternehmen glänzend gerechtfertigt. Als nämlich die Kunde von Kegila's Noth zu David gelangte, fehlte es diesem gewifs nicht an Lust, den Hülferuf zu erhören. Die Bedenklichkeit des Zuges konnte er sich aber nicht verhehlen; darum erforschte er den Willen Jahve's, und es ist für unsere jetzige Betrachtung gleichgültig, ob dies durch einen Propheten, oder durch das vor dem Jahvebild durch Ebjathar geworfene heilige Loos geschah. Die Entscheidung fiel zu Gunsten des Zuges aus. Dennoch (vgl. Jer. 43, 1 ff.) genügte diese Entscheidung den Leuten Davids noch nicht, da den Kurzsichtigen das Unternehmen gar zu unklug erschien; wir sehen, wie schwer das noch von Duncker geltend gemachte Bedenken wog. Der weiter blickende und auf die Antwort Jahve's bauende David beruhigte sich bei der Weigerung seiner Leute nicht, sondern befragte Jahve's Willen zum zweiten Male. Als nun dieselbe Entscheidung wiederum erfolgte, gelang es David, seine Leute willig zu machen; der Zug warde unternommen, 
das Philisterheer geschlagen, Kegila befreit. Auf's Neue hatte der berühmte Philisterkämpfer sich dem Erbfeind seines Volkes furchtbar gemacht. Der vor Saul geflohene David stand auch jetzt, obgleich Saul ihn öffentlich als Reichsfeind brandmarkte, als der alte nationale Held Israels da, und dieser Nimbus konnte sich auch später nicht ganz verlieren, als David durch Sauls Schuld sich in den Schutz der Philister flüchten mufste. Zu ihrem Erstaunen erkannten die bei Kegila geschlagenen Philister die Macht des von Saul getrennten David. War es nun kluge Politik, dafs sie zu Davids Verderben sich mit Saul verbündeten? Daran können wir doch im Ernst nicht denken. Ein Feind, der zu schaden vermag, kann auch ein werthvoller Bundesgenosse sein. Es war für die Philister schon werthvoll, dafs sich die Kraft Sauls gegen David verzehrte. Je heftiger Saul den David verfolgte, und zwar vergeblich verfolgte, aufser dafs er den Unschuldigen fast in die Stellung eines Nebenbuhlers des Königs hineindrängte, desto wichtiger wurde für die Philister die Persönlichkeit des angeblichen Kronprätendenten, desto werthvoller mulste ihnen die Freundschaft Davids erscheinen, wenn sie auch nur darin bestand, dafs er dem Saul nicht mehr half durch Bekämpfung der Philister. An ein Bundesverhältnifs zwischen David und den Philistern ist für die Zeit, ehe der judäische Häuptling Vasall des Achis wurde, gewifs nicht zu denken. Notbwendig jedoch erscheint mir die Annahme eines stillschweigenden thatsächlichen Abkommens, denn David hatte nach seinem Siege bei Kegila allen Grund, seine Feindseligkeiten gegen die Philister für lange Zeit gänzlich einzustellen. Die alten Feinde liefsen dann, weil David sie nicht mehr belästigte, sondern ihnen nützlich war, auch ihrerseits den David in Ruhe, so dafs sich die friedlichen Beziehungen zwischen beiden Theilen bildeten, ohne welche der schliefsliche Uebergang Davids auf das Gebiet des Achis gar nicht möglich geworden wäre. 
Duncker leugnet nicht, dals David sich vorübergehend der festen Stadt Kegila bemächtigt habe. Das soll aber erst geschehen sein, nachdem er sich durch die Heirath mit der reichen Abigail gestärkt und (S. 108) erlangt hatte, dafs sich die 1 Sam. 30, 26-31 genannten südlichen Orte Juda's für ihn erklärten. Die am Schlufs von Kp. 30 erzählte Vertheilung amalekitischer Beute an befreundete Aelteste Juda's war gewifs eine kluge Mafsregel, ähnlich wie die Zurückforderung der Michal und vieles Andere; aber diese Beutevertheilung fällt doch in die Zeit von Sauls Tod, geraume Zeit später als Davids ziemlich unstätes Freibeuterleben. Den Versuch, seine Landsleute zum Aufstande gegen Saul zu bewegen, hat der historische David nie gemacht; daher sagt Duncker auch mit Unrecht : „David hatte wohl darauf gerechnet, grölseren $\mathrm{Zu}$ lauf im Stamme Juda zu finden. So lange sein Anhang auf vier- oder sechshundert Mann beschränkt war, vermochte er nur ein Räuberleben mit dieser Schaar zu führen. ${ }^{*}$ Die heimlichen Anhänger Davids waren sicher viel zahlreicher als die paarhundert Mann seines kleinen Heeres, welches für seine freibeuterischen $\mathrm{Zwecke}$ grols genug, aber niemals dafür bestimmt war, dem Heerbanne Israels unter Saul entgegenzutreten. Nicht durch Dämpfung des angeblichen Aufstandes wurde David zum Uebertritt auf das Philistergebiet gezwungen, sondern aus dem einfachen Grunde, welchen 1 Sam. 27, 1 angiebt. Die Hoffnung, dafs Saul endlich von seiner Verfolgung ablassen werde, hatte sich eben nicht erfüllt; um Ruhe und Sicherheit nach den erlebten Gefahren zu gewinnen, mufste David schliefslich in der Philister Land entrinnen, denn in Juda, wo der König natürlich noch viele Anhänger hatte, war Sauls Macht so grofs, dafs der Flüchtling sich hier auf die Dauer nicht halten konnte. Wenn Wellhausen (Skizzen I, S. 23) sagt : „Auf die Dauer konnte David sich in Juda vor Sauls Verfolgung nicht halten, zumal seine Landsleute 
im Allgemeinen nicht auf seiner Seite standen“, so kann ich der letzteren Behauptung nur in dem Sinne beipflichten, dafs die Masse der Judäer an Aufstand gegen den König, welchen dieser blutig gerächt haben würde, eben so wenig dachte, als David selber solche offene Parteinahme gegen Jahre's Gesalbten jemals gewünscht hat. Treffend fährt Wellhausen fort : „David that einen verzweifelten Schritt und stellte sich dem Philisterkönig Achis von Gath zur Verfügung. Der empfing ihn mit offenen Armen und wies ihm die Stadt Siklag zum Wohnsitz an. Hier trieb er mit seiner Schaar das alte Wesen weiter, als selbständiger Fürst, jedoch mit der Verpflichtung Heeresfolge zu leisten. " Wie Wellhausen nicht bezweifelt, dals David zu Hebron Vasall der Philister war, so will er natürlich durch die Behauptung, David habe das frühere Freibeuterleben in Ziklag als selbständiger Fürst fortgesetzt, nicht leugnen, dafs jetzt der Schützling der Philister durch eingegangene Verpflichtung sich in ein Abhängigkeitsverhältnifs begeben hatte. David machte sich zur Heeresfolge verbindlich, und zwar, wie sich unter den gegebenen Umständen von selbst versteht, zur Heeresfolge gegen Saul und seine Landsleute, wie er dieselbe denn nach dem Bericht 1 Sam. 29 auch wirklich geleistet hat.

So war denn David, wie Stade (Gesch., S. 253) vortrefflich sagt, in eine bedenklich schiefe Stellung gerathen. Er, der einst gefeierte Vorkämpfer Israels gegen die Philister, stand jetzt in deren Diensten. Das Vertrauen seiner neuen Herren vermochte er sich bei dieser Vergangenheit nur durch Thaten zu erwerben, welche die Liebe seines Volkes zu ihm ersticken mufsten. Ein weniger kluger und energischer Mann wäre an den Schwierigkeiten dieser Stellung wohl gescheitert. Nicht so David." Doch ich bitte den Leser, den ganzen schönen Absatz in Stade's Buch für sich weiter zu lesen; vielleicht ist er dann eben so erstaunt wie ich, wenn er desselben Gelehrten Aeufserung 
(Stade, S. 252) dagegen hält, dafs 1 Sam. 27, 8-12 nein wenig glaubwürdiges Histörchen und dazu noch späterer Zusatz" sei.

Auf dem vielfach veralteten Standpunkte, welchen noch Duncker's fünfte Auflage einnimmt, begreift sich das absprechende Urtheil über den Schlufs von 1 Sam. 27 vollkommen, während ich es bei Wellhausen und Stade sehr auffällig finden mufs. Doch hören wir zunächst die Bedenken des zuerst genannten Gelehrten. Duncker meint

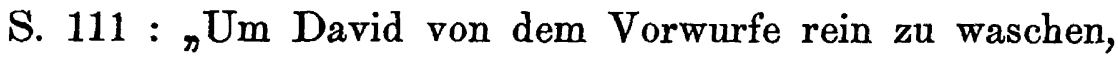
dafs er mit den Philistern gegen sein Volk gekämpft, wird 1 S. 27, 8-11 bemerklich gemacht, dafs David stets gegen die Stämme der Wüste gezogen sei, die Gefangenen niedergehauen habe und dem Achis erzählt habe, er sei in den Süden Juda's eingebrochen. Zu Einfällen in die Wüste war die Lage von Ziklag wenig geeignet; auch hatte ihm Achis nicht dazu ein Gebiet gegeben, um gegen die Söhne der Wüste zu kämpfen. Achis sagt späterhin von David, er habe an ihm nichts gefunden seit seinem Uebergang $(29,3.6)$, er will ihn sogar zum Hüter seines Hauptes setzen $(28,2)$, und eine solche Täuschung, wie dem David hier zugeschrieben wird, setzt voraus, dafs Achis und alle übrigen Philister blind gewesen wären." Sehr interessant ist dabei, dafs Duncker an $1 \mathrm{Sam} .27,12$ nichts auszusetzen findet; die hier befindliche Nachricht, dafs Achis dem David Vertrauen schenkte und glaubte, er habe sich durch Bekämpfung der eigenen Landsleute bei seinem Volke für immer verhalst gemacht, findet Duncker mit vollem Recht glaubwürdig, wie sie denn für das Verständnifs des geschichtlichen Zusammenhangs gradezu unentbehrlich heilsen mufs. Da Duncker dem David alles Mögliche zutraut, ihn also unbedenklich gegen sein Volk kämpfen läfst, so braucht er sich nicht einmal dadurch von seiner Voraussetzung abbringen zu lassen, dafs er sie nicht beweisen kann, sondern schliefst S. 111 mit 
der bundigen Erklärung : „Für die Beurtheilung Davids genlugt, dafs es an seinem Willen (gegen Saul) mitzufechten nicht gelegen hat." Nicht die Kurzsichtigkeit ${ }^{1}$ ) der Philister (Stade, S. 253) bewahrte den David vor der Theilnahme an der Schlacht, welche Saul den Untergang brachte, sondern der gerechte Argwohn der anderen Philisterfursten, die nicht blind waren, während Achis sich hatte täuschen lassen. So wenig Blucher, wenn es von $\mathrm{ihm}$ abgehangen, dem schwedischen Kronprinzen und fruheren französischen Marschall den Oberbefehl uiber die Nordarmee anvertraut hätle, eben so wenig wollten die Philister den David mit in die Schlacht gegen seinen König nehmen. Es ist fruchtlos, daruber zu speculiren, was David gethan hätte, wenn die Zurucksendung, gegen welche der Judäer natúrlich zur Aufrechterbaltung seiner Rolle sich etwas sperren mufste, nicht erfolgt wäre. $\mathrm{Ob}$ David durch Verrath an den Philistern, durch Uebergang zu seinen Landsleuten diesen den Sieg verschafft baben wurde, was mir sehr unwahrscheinlich vorkommt, ob er in der Schlacht den Tod gesucht und gefunden, oder ob er's vielmehr fertig gebracht hätte, für die eigentliche Entscheidungsschlacht zu spät anzukommen - wer will das sagen? Ich zweifle nicht, dafs David trotz all seiner "Klugheit und Energie" als Lehnsträger des Achis sich in sehr unbehaglicher Stellung befand, aber nicht nur aus Besorgnifs, sein falsches Spiel könnte aufgedeckt werden, sondern auch darum, weil die ihm durch die Verhältnisse

1) Jedenfalls würde man wohl von Kurzsichtigkeit des spanischen Karl V., der don Herzog Moritz an seines Vetters Statt zum Kurfürsten von Sachsen machte, nicht darum sprechen, weil Moritz den Kaiser später zum Vertrage von Passan gezwungen hat. Die Philisterfürsten hielten sich an das, was sie von Davids Vorgangenheit sicher wufsten und mochten die Vertrauensseligkeit des ihnen bekannten Achis nicht theilen, wenn sie auch dem David aus der letzten Zeit nichts Schlimmes beweisen konnten. 
aufgenöthigte Rolle seiner edlen Natur widersprach, weil Grausamkeit und Lüge, nach dem zu urtheilen, was wir geschichtlich von David wissen, ihm viel schwerer fallen mufsten, als ich das z. B. von einem Napoleon I. annehmen möchte. Den höchsten Gipfel erreichte Davids Noth, als er die Heeresfolge gegen Saul leisten sollte, zu welcher er sich bei seinem Uebertritt auf das philistäische Gebiet verpflichtet hatte. Lange mochte er gehofft haben, dafs es gar nicht zu der gefürchteten Forderung kommen werde, dafs die Philister nicht Ernst damit machen würden, ihn wirklich in den Krieg mitzunehmen, wie sie ja thatsächlich, Davids Hoffnung erfüllend, noch vor Eröffnung der Feindseligkeiten den Judäer wieder zurückgeschickt haben. Ich zweifle nicht, dafs David für diese Schickung Jahve, seinem Gott, von Herzen gedankt, der ihn vor dem Schlimmsten gnädig bewahrt hat.

Von den bekannten fünf Philisterstädten lagen Asdod, Askalon und Gaza am Meere, im Binnenlande Ekron und wahrscheinlich südwestlich von diesem Gath, während Ziklag mit Conder und Kitchener, Furrer, Köhler (II, S. 226), Mühlau (in Riehm's HWB.) wohl an der Stelle des heutigen Zuheiliḳa zu suchen ist, so dafs Duncker's von der Lage Ziklags entnommener Einwand hinfällt. Wenn Duncker ferner meint, Achis habe dem David nicht dazu ein Gebiet gegeben, dafs er gegen die Wüstensöhne kämpfe, so ist diese Behauptung theils irrig, theils selbstverständlich richtig. Als David mit seiner Kriegerschaar nach Gath zog, um das Abkommen mit Achis zu vereinbaren, konnte schwerlich einer von beiden Theilen daran denken, dafs der ganze Haufe der Krieger sammt ihren Familien (vgl. 1 Sam. 27, 3; 30, 2 f.; 2 Sam. 2, 3) in der Residenz Gath unterzubringen sei. Man darf sich durch die etwas ungeschickte ${ }^{1}$ ) Art der Erzählung nicht täuschen

1) Besonders auffallig ist der Umstand, dafs in 1 Sam. 27, $3 \mathrm{zu}$ 
lassen, welche vorgreifend die Hauptsache, dafs Saul auf die Verfolgung des in den Schutz des Königs von Gath geflohenen David verzichtet (1 S. 27, 1. 4), und dann erst genauer die Uebersiedelung nach Ziklag berichtet. Nicht ein Gebiet, wohl aber die Stadt Ziklag hat David zum Wohnsitze für sich und seinen Haufen erhalten; wahrscheinlich bildete die Ueberweisung dieser für Davids Zwecke sehr gelegenen Stadt einen wichtigen Theil der Vereinbarung, welche David beim Uebertritt auf das Philistergebiet mit Achis traf, so dafs der vorläufige Aufenthalt in oder bei Gath nur so lange Zeit währte, als zum Feststellen der beiderseitigen Vertragsbedingungen erforderlich war. Dem entspricht die richtige Stellung der Angabe über die Dauer von Davids Wohnen im Philisterlande in V. 7, nachdem V. 5. 6 kurz die Uebersiedelung nach Ziklag erzählt ist, nicht aber nach V.4. Wenn nun Achis Ziklag und seinen Schutz dem David gewährte, was gab dieser seinerseits dem Achis? Mit vollem Recht urtheilt Duncker (S. 106) : „Die Philister hätten einen Gegner, der ihnen so schweren Abbruch gethan, nicht ohne Weiteres aufgenommen, wenn er sich nicht offen von Saul losgesagt und ihnen die Meinung gegeben hätte, ihren Kampf gegen Saul und Israel forthin zu unterstützen." Ich denke, -dafs sich dies sehr gut mit der von mir vertheidigten Thatsache verträgt oder mit der

\footnotetext{
"Also blieb David bei Achis" noch hinzugefügt wird „zu Gath". Ich mache aber darauf aufmerksam, dafs diese Hinzufügung in LXX cod. Vat. fehlt und vielleicht der alten Davidsgeschichte nicht zur Last fällt. Der Text in Kp. 27 ist ja mehrfach verderbt. Sicher dagegen gehört dem alten Erzähler die Betonung der Weiber an, und mit Fleifs spricht er nicht nur von den Weibern Davids, sondern (V. 3 : ein jeglicher mit seinem Hause) auch von denjenigen seiner Krieger. Die Frauen konnten nicht so rasch fliehen wie die Krieger und durften doch nicht im Stich gelassen werden; die Rücksicht auf die Ruhe und Sicherheit der Familien mufste also zu Davids schwerem Entschlufs, auf's Philistergebiet überzutreten, stark mitwirken.
} 
Behauptung, dals David in Wirklichkeit nie gegen sein Volk gekämpft hat. Man denke doch nicht, dafs David als ein armer Schutzflehender nach Gath kam; er war „der Führer einer siegreichen, in harter Kriegsarbeit gestählten Schaar" (Stade, S. 253), den die Philister „mit offenen Armen" aufnahmen, wenn er ihnen nur die nöthigen Garantien bot, dafs sie keinen Schaden, sondern Nutzen von ibm haben würden. Diese Garantien glaube ich aber noch reichlicher nachweisen zu können, als gewöhnlich von denjenigen geschieht, welche David gegen sein Volk kämpfen lassen.

Zunächst weise ich auf die von mir als wahrscheinlich aufgezeigte Thatsache hin, dafs David schon vor seinem Kommen zu Achis mehrfach Gelegenheit gehabt und benutzt hat, den Philistern seine Nützlichkeit zu erweisen; in der persönlichen Verhandlung mit Achis wird David das gewils in's hellste Licht gestellt haben. Ferner nehme ich an, dafs David durch feierlichen Schwur bei Jahve, dem Gott Israels, dem Achis versprochen hat, wenn Achis gegen Saul ins Feld ziehen würde, dem Könige von Gath Heeresfolge, zu leisten. Endlich wird sich Achis schwerlich mit der Aussicht, dafs David ihm nicht schaden werde, zufrieden gegeben, sondern auch positiven Nutzen verlangt haben, d. h. einen bestimmten Antheil der Beute, welche David auf seinen Streifzügen gegen die beiden Theilen nun gemeinsamen Feinde im Negeb machen würde. Für David war eine Hauptsorge, dafs er für den Lebensunterhalt seiner Leute, welchen Achis sicher nicht bestritt, den nöthigen Schutz und Zuschufs verschaffte, und beides geschah durch kleine Kriegs- und Streifzüge gegen Beduinenstämme, welche David nach jedesmaligem eigenen Ermessen und zugleich im Interesse seines Lehnsherrn unternahm. Achis konnte nichts dagegen haben ${ }^{1}$ ), dafs David

1) Wir lesen bei Ferd. Justi a. a. O. : „Zuletzt begab sich David 
sein altes Freibeuterleben gewissermafsen von Ziklag aus fortsetzte, mufste vielmehr es gerne sehen, wenn David die unbändigen südlichen Stämme, von denen auch die Philister leicht belästigt wurden, im Zaume hielt, und ihm seinen Beutetheil richtig nach Gath ablieferte.

Heilst es nun „David rein waschen", wenn die alte Quellenschrift, der 27, 8-11 nicht minder als 27, 12 angehört, hier gerade das erzählt, was Duncker als sachlich nothwendig fordert? Gewifs hat David dem Achis die Meinung beigebracht, dafs die Beute den Israeliten abgenommen werde und David sich dadurch bei seinen Landsleuten sehr verhafst mache. Das Vorgeben Davids, dafs seine wiederholten Streifzüge den im äufsersten Süden wohnenden Judäern, Jerahmeelitern und Kenitern gegolten hätten, war nach Köhler's (II, S. 228) richtiger Auslegung „um so leichter möglich, als die angeblich und die wirklich von ihm befehdeten Stämme dicht bei einander wohnten, mithin beim Auszug Davids aus Ziklag kein Philister das eigentliche Ziel des Zuges vorausbestimmen konnte und David endlich auch durch Niedermetzelung sämmtlicher Gefangenen dafür Sorge trug, dals Niemand den wirklichen Sachverhalt Achisch verrathe (V. 9. 11). " Den Schafen, Rindern, Eseln, Kameelen und Kleidern konnte der Philisterkönig nicht ansehen, woher sie kamen. Die Streifzüge, welche selbstverständlich von Ziklag (V. 8) ausgingen, nahmen hier auch ihr Ende. Statt der Schlufsworte von V. 9 „und kehrte zurück und kam zu Achis" hätte ein weniger kurz schreibender Erzähler sagen können : „und David kehrte nach Ziklag zurück und brachte dann einen Theil der Beute zu Achis nach Gath. ${ }^{*}$ Aber V. 9 ist vollkommen deutlich, und ich weifs nicht, ob schon Jemand

mit seinen Leuten in den Dienst des Philisterkönigs Achis von Gath, der ihn dazu ausersah, die südlichen Nomadenstämme von Tsiqlag aus im Zaum zu halten, was auch mit gehörigem Nachdruck ausgeführt wurde (1 Sam. 27)." 
vor Wellhausen ihn mifsverstanden hat; ganz dasselbe gilt von V. 11, wo die Residenz des Achis in der Begründung von Davids Grausamkeit erwähnt wird. Auf seinen Streifzügen konnte David es schwer vermeiden, dals er nicht ab und zu auch durch seinen Landsleuten zugehöriges Gebiet kam, welche leicht merkten, dafs er ihnen vor wie nach freundlich gesinnt war, und ihn daher gerne unterstützten, wie sie sich vor der Uebersiedelung Davids nach Ziklag für den Schutz ihrer Heerden dankbar gezeigt hatten. Was hindert uns nun anzunehmen, dafs David, der beinahe Nabal mit seinem ganzen Hause umgebracht hätte (1 Sam. 25, 34), in einzelnen seltenen Fällen eine ihm von einem unvorsichtigen Anhänger Sauls angethane Schmach blutig gerächt hat? Ich meine nicht, dals David die Treue gegen Saul verfolgt hätte; dazu war der jetzt von den Philistern Abhängige wahrscheinlich viel zu klug. Die Landsmannschaft, welche sich besonders in dem Bekenntnifs zu Jahve zeigte, hat David als solche gewifs niemals verfolgt. Aber persönliche Beleidigungen wird sich David schwerlich haben gefallen lassen, zumal da er, wenn einmal eine solche an einem Landsmann zu strafen war, leicht dafür sorgen konnte, dals die Strafe seinen guten Beziehungen zur übrigen Landsmannschaft nicht schadete; sicher aber wird David einen solchen Ausnahmefall, wenn er wirklich einmal einen Landsmann züchtigte, dem Achis gegenüber ausgiebig verwerthet haben.

Sehen wir nun zu, ob die neuesten Bestreiter der Geschichtlichkeit von 1 Sam. 27, $8 \mathrm{ff}$. bessere Gründe ins Feld führen, als die wohl genügend widerlegten, welche Duncker vorgebracht hat. Während Wellhausen in seiner Licentiaten-Dissertation (De gentibus etc., Gott. 1870, pg. 25.39 sq.) 1 Sam. 27,10 noch eben so glaubwürdig fand als 1 Sam. 30, 29, hat ihn schon seine Untersuchung des Textes der Bücher Samuelis (Gött. 1871, S. 140) zu der seitdem von ihm (Bleek ${ }^{4} \S 109$ ) festgehaltenen und 
von Stade angenommenen, aber nicht ernstlich weiter begründeten gegentheiligen Ansicht geführt. Vielleicht geben meine Bemerkungen Anlals zu einer einleuchtenderen Bestreitung der angefochtenen Stelle, wenn der Angriff nicht eingestellt wird. In der ersten Anmerkung der eben angeführten Seite 140 sagt Wellhausen : ${ }_{\text {V }}$. $7-12$ leidet an unüberwindlichen inneren Schwierigkeiten und widerspricht dem Vorhergehenden und Folgenden, sofern nicht Siklag, sondern Gath als Ausgangspunkt vorausgesetzt wird. Cap. 30 setzt keineswegs das hier Erzählte voraus." Ueber die exegetisch falsche Meinung, Gath sei als Ausgangspunkt von Davids Streifzügen gedacht, ist wohl kein Wort mehr zu verlieren; ich begreife es, dafs Köhler, der sonst auf die Einwände der neueren Ausleger so sorgfältig Rücksicht nimmt, über den handgreiflichen Auslegungsfehler mit Stillschweigen weggegangen ist. Auch das argumentum ex silentio, dals man in Kp. 30, wo Ziklag's Heimsuchung durch die Amalekiter in Davids Abwesenheit erzählt wird, durchaus Bezugnahme auf 27, 8 erwarten müsse, wiegt nur sehr leicht. Gewifs hätte der Erzähler in Kp. 30 sagen können, dals die Amalekiter mit dem Ueberfall von Ziklag zugleich Rache für das nahmen, was sie selbst erst kürzlich von David erfahren hatten. Aber er brauchte es nicht zu sagen, weil jedem israelitischen Leser die alte Feindschaft zwischen Israel und dem noch von Saul so nachdrücklich bekriegten Amalek grade so gut bekannt war, als die räuberische Natur dieses Volkes. Oder sollen die Worte „Cap. 30 setzt keineswegs das hier Erzählte voraus" einen inneren Widerspruch zwischen beiden Berichten aussagen? Ich kann keinen Widerspruch finden und mufs den Beweis für eine solche Behauptung abwarten. Vielleicht soll das ein Widerspruch sein, dafs David die gefangenen Amalekiter umbringt, während diese die weggeschleppten Weiber und Kinder ihres Feindes und seiner Krieger am Leben lassen. Warum 
aber sollten die Beduinen sich der ihnen so werthvollen menschlichen Beute durch Tödtung beraubt haben, da nicht einmal feststeht, dafs David auch nur ein einziges amalekitisches Weib hatte müssen umbringen lassen $\left.{ }^{1}\right)$ ? Wenn nun der von Wellhausen blofs mit "sofern" begründete Widerspruch nicht nachweisbar ist, so weifs man nicht, ob dasselbe von den „unüberwindlichen inneren Schwierigkeiten" gilt, oder ob dieselben anderswo liegen. Vermuthlich ist der exegetische oder textkritische Anstol's in 1 Sam. 27, 8 gemeint, die schwer zu hebende Schwierigkeit des überlieferten Textes, über welche „das späte Alter ${ }^{\text {“ dessen, }}$ der den Einschub geschrieben habe, angeblich „einigermalsen tröstet."

Wäre es wirklich der Fall, dafs in 1 Sam. 27, 8-12 eine sprachliche Erscheinung vorläge, die wir nur einem jüngeren, vom Verfasser der alten Davidsgeschichte verschiedenen Schriftsteller zuschreiben könnten, so genügte dies für sich noch lange nicht zur Begründung der Annahme, dafs der ganze Abschnitt ein Einschub und obendrein ein inhaltlich unglaubwürdiger Einschub sei; bekanntlich gibt's auch durchaus glaubwürdige Einschiebsel, z. B. 2 Sam. 2, 11. Eine vereinzelte Schwierigkeit stellt sich ja oft genug als ein blol'ser Textfehler heraus, so dafs man nicht einmal spätere Ueberarbeitung zu Hülfe zu nehmen braucht. Ich vermisse nun völlig den Nachweis, dals die Verse 1 Sam. 27, 8-12 nach ihrem sprachlichen

1) Den drei Namen von 27, 10 entspricht die Dreizahl in V. 8, welche ich nicht darum mit Wellhausen und Köhler auf eine Zweizahl zurück führen möchte, weil wir (vgl. Jes. 10, 31) die Girsiter oder Gisriter des Negeb sonst nie erwähnt finden. Es kommen also aufser den Amalekitern noch mehrere andere Stämme in Betracht, so dafs sich auf die letzteren das Umbringen von „Mann und Weib* beschränken konnte. Irrig behauptet Thenius, die V. 8 genannten Völker seien mit den Philistern befreundet gewesen, weil sich sonst David das Umbringen der Gefangenen hätte ersparen können. 
Gesammtcharakter der Quelle, aus welcher der Anfang des Kapitels stammt, nicht angehören könnten, glaube vielmehr, dafs durch Textverbesserung, welche im Samuelbuch häufig auch dort, wo sie uns nicht recht gelingen will, unverkennbar nöthig ist, auch 1 Sam. 27, 8 geholfen werden mufs, da mir die Erklärung von V. $8 \mathrm{~b}$ als Einschiebsel unwahrscheinlich vorkommt. Warum es im Süden Juda's keine Gessuriter soll gegeben haben können, ist mir unverständlich; ich finde diese Annahme (vgl. Köhler I, S. 81 Anın. 5 und Mühlau in Riehm's HWB. S. 5(18) viel leichter als Wellhausen's Erklärung nach 1 Kön. 9, 16 (vgl. HWB., S. 500 f.), und an das syrische Gesur (2 Sam. $15,8)$ ist ja überhaupt nicht $z u$ denken. Was aber den eingestandenermafsen verderbten Text von V. $8 \mathrm{~b}$ betrifft, so ist der Anstols, welchen Thenius an „von Alters her" aus guten Gründen nimmt, mit Wellhausen und Köhler (U, S. 176) nach 1 Sam. 15, 4. 7 leicht zu heben. Im Anschlufs an Wellhausen, S. 140, Anm. 2 gewinnen wir den von unserem genialen Luther ausgedrückten Sinn „denn diese ( $($ statt נ) waren die Einwohner des Landes", wenn wir statt des weiblichen Singulars die männliche Pluralform des Particips (vgl. 1 Sam. 23, 5; 31, 11) lesen, hier also nur Einen Buchstaben ändern. Den Schlufs von 1 Sam. 27, 8 (Landes, -welches von Telam bis nach Sur sich erstreckt u. s. w.) brauchen wir nicht weiter zu besprechen. Ich habe eine vollständige Auslegung der Verse 8-12 jetzt nicht zu geben und bemerke daher nur noch, dals in V. 10 , heute ${ }^{*}$ nicht geprelst werden darf, sondern ähnlich unserm, diesmal ${ }^{*}$ auf den eben beendigten Streifzug hinweist, und endlich, dafs ich in der Construction von V. 11 jetzt Köhler (II, 227, Anm. 2) gegen Ewald, Luther und Bunsen's Bibelwerk Recht gebe.

Im Jahre 1878 (Bleek ${ }^{4}$ S. 220) hat Wellhausen wiederholend, aber etwas deutlicher unsere Verse für einen späten Zusatz erklärt, „der an unüberwindlichen inneren 
Schwierigkeiten leidet, und sofern nicht Ziklag, sondern Gath als Ausgangspunkt der Razzia's vorausgesetzt wird, dem Vorhergehenden und Folgenden widerspricht. Zur Motivirung von c. 30 ist keineswegs das hier Erzählte nothwendig." Das Letztere ist gewifs richtig; welches aber die von dem angeblichen Widerspruch unterschiedenen unüberwindlichen inneren Schwierigkeiten seien, erfahren wir noch nicht. Die Belastung Davids mit wiederholter Lüge ${ }^{1}$ ) ist nicht so schlimm als die mit wiederholter Grausamkeit. Da aber die dem David so günstige alte Quellenschrift diese ungünstigen Dinge meldet, so haben sie um so mehr die Vermuthung für sich, dafs sie wirkliche Thatsachen sind. Gewifs erleichtert sich Köhler die Denkbarkeit von Davids mit Achis getriebenem doppelten Spiele in hohem Grade, wenn er es nicht mit Luther 16 Monate dauern läfst, sondern nur 4 Monate lang (LXX cod. Vat.); für jeden aber, der die Sache an sich undenkbar findet, macht die Zeitdifferenz schwerlich einen durchschlagenden Unterschied. Ich lege auf die chronologische Notiz in 27, 7 kein Gewicht; ist's ein Einschiebsel, wie Wellhausen behauptet, so braucht's darum doch noch nicht auf 29, $3 \mathrm{zu}$ beruhen, wo von Monaten keine Rede ist. Zum Bruche Davids mit Achis ist es auch lange Jahre nach Sauls Tod noch nicht gekommen. Ich habe schon

1) Die Geschichtlichkeit der Nothlüge (1 Sam. 21, 3 ff.) gegen Ahimelech steht fest. Einige Waffen und Brote hätte der Flüchtling auch anderswo finden können, als bei den Priestern zu Nob. Das, was den Saul so erbitterte, und was Doeg 1 Sam. 22, 10 an erster Stelle nennt, war der Umstand, dafs der Priester Jahve für David befragt (vgl. 22, 15) und ihm ohne $\mathbf{Z}$ weifel eröffnet hat, Davids gegenwärtige, dem Ahimelech unbekannte Unteruehmung werde guten Erfolg haben. Dadurch machte David, der seine Nothlüge sich gewifs nicht als grofse Sünde angerechnet hatte (doch vgl. 22, 22), die Priester zu Nob in des Königs Augen zu seinen Mitverschworenen. In den Augen Ferd. Justi's haben die Priester wirklich ${ }_{n}$ dem Vorgehen Davids ihre priesterliche Sanktion ertheilt!" 
erwähnt, dafs Stade, der 1 Sam. 27, 1-6 als eine Erzählung von durchaus historischem Gepräge anerkennt und V. 7 eine sehr ungeschickte Wiederholung aus 29, 3 nennt, von der Glaubwürdigkeit der V. 8-12 nichts wissen will. Leider wird dafür kein anderer Grund als der exegetische Irrthurn angegeben, dafs David die für ihn nicht grade rühmlichen Streifzuge von Gath aus unternommen haben soll, während David auch nach 1 Sam. 30 seine Kriegszüge von Ziklag aus unternimmt. Mit demselben Recht könnte man aus dem heute $^{*}(27,10)$ herauslesen, dals David täglich einen Streifzug ausgeführt habe, und aus der Erwähnung der ägyptischen Grenze in V. 8 folgern, dals die Streifzüge sich bis zu dieser erstreckten. Lassen wir aber alle irrigen Uebertreibungen bei Seite und bedenken auch, dafs in den Aufständen des Absalom und Seba Davids Krieger viel mehr Israeliten getödtet haben werden, als sie auf den Zügen von Ziklag aus fremde Beduinen erbarmungslos über die Klinge springen liefsen, schlimm genug bleibt Davids Benehmen doch in jedem Fall und läfst sich nur durch seine damalige Nothlage einigermafsen entschuldigen, niemals rechtfertigen. Worin aber die unüberwindlichen inneren Schwierigkeiten der Erzählung liegen sollen, das ist mir bisher nicht klar geworden. Wenn man meint, Achis hätte Davids eitles Vorgeben durchschauen müssen, da ja unmöglich sei, dafs von Davids wirklichem Treiben gar keine Kunde nach Gath gelangt wäre, so übersieht man ganz, dafs es doch nicht so leicht war, den bei Achis sehr beliebten Helden in des Königs Augen seiner Täuschung zu überführen. Natürlich gelangten die Beutezüge nicht über Gath nach Ziklag, sondern zuerst nach Ziklag, wo sich David zuverlässige Leute aussuchte, welche die für Achis sorgsam ausgewählten Beutestücke nach der Residenz hinbrachten. Man mag es auffällig finden, dals Achis sich von dem redegewandten und um keine Auskunft verlegenen David hintergehen 
liefs. Allein psychologisch undenkbar kann ich es nicht nennen, dafs der so viele Leute bezaubernde David auch den Achis, nicht jedoch dessen fern wohnende Mitfürsten, dermafsen für sich einnahm, dafs er keinen gegentheiligen Vorstellungen, an welchen es gewifs nicht gefehlt hat, Gehör geben mochte, vielmehr an David nichts Schlimmes zu finden $(29,3)$ wufste. Mögen die über solche Verwendung für David sehr aufgebrachten Philisterfürsten den Glauben des Achis noch so einfältig gefunden haben, ich kann es nicht für unmöglich halten, dals der allerdings leichtgläubige Achis diesen Glauben hegte und festhielt. Für uns stellt sich die Frage nur dahin, ob David blofs den Schein erwecken mufste, dafs er Sauls Unterthanen als seine eigenen Feinde ansehe und behandle, oder ob er sich, lediglich von Selbstsucht und Ehrgeiz getrieben, unbedenklich zur Bekämpfung seiner Landsleute hergab. Wer der letzteren Annahme folgt, der befreit allerdings den Achis von dem Vorwurf der Leichtgläubigkeit, auch den David selbst von den schlimmen Dingen, welche ihm 1 Sam. 27, 8-12 zur Last gelegt werden; aber die Bestreiter der Glaubwürdigkeit dieser Erzählung, die zum Theil auch den David als Vasallen der Philister von Hebron aus über Isboseths freie Unterthanen Siege erkämpfen lassen, mögen doch zusehen, ob sie nicht wirklich unhistorische Züge in das Bild Davids hineinmalen. 